\title{
SL9 impact chemistry: Long-term photochemical evolution
}

\author{
By J UL I A N NE I. MOSES
}

Lunar and Planetary Institute, 3600 Bay Area Blvd., Houston, TX 77058-1113, USA

One-dimensional photochemical models are used to provide an assessment of the chemical composition of the Shoemaker-Levy 9 impact sites soon after the impacts, and over time, as the impact-derived molecular species evolve due to photochemical processes. Photochemical model predictions are compared with the observed temporal variation of the impact-derived molecules in order to place constraints on the initial composition at the impact sites and on the amount of aerosol debris deposited in the stratosphere. The time variation of $\mathrm{NH}_{3}, \mathrm{HCN}, \mathrm{OCS}$, and $\mathrm{H}_{2} \mathrm{~S}$ in the photochemical models roughly parallels that of the observations. $S_{2}$ persists too long in the photochemical models, suggesting that some of the estimated chemical rates constants and/or initial conditions (e.g., the assumed altitude distribution or abundance of $\mathrm{S}_{2}$ ) are incorrect. Models predict that CS and CO persist for months or years in the jovian stratosphere. Observations indicate that the model results with regard to CS are qualitatively correct (although the measured CS abundance demonstrates the need for a larger assumed initial abundance of CS in the models), but that CO appears to be more stable in the models than is indicated by observations. The reason for this discrepancy is unknown. We use model-data comparisons to learn more about the unique photochemical processes occurring after the impacts.

\section{Introduction}

The Shoemaker-Levy 9 (SL9) impacts generated strong shocks in the jovian atmosphere in two distinct altitude regions: in the deep stratosphere or troposphere where strong deceleration of the comet fragments and maximum energy release occurred, and in the upper stratosphere where the impact plumes splashed back down into the atmosphere. Shocked, thermochemically processed cometary material and tropospheric jovian air were deposited in Jupiter's stratosphere after the impacts. The new impact-derived sulfur-, nitrogen-, oxygen-, and carbon-bearing molecules evolve with time due to solar ultraviolet photolysis, chemical reactions, vertical and horizontal transport, and condensation/aerosol formation. Because continuous observational coverage of the impact sites was not possible and because many of the potential impact-derived species are difficult to observe, photochemical models play an essential role in assessing the chemical state of the jovian atmosphere in the hours, days, and months following the impacts. We compare photochemical model predictions with observations in order to better define chemical abundances immediately after the impacts and to evaluate the long-term evolution of the impact-derived species.

The molecular species either detected for the first time in Jupiter's stratosphere or found to be enhanced after the SL9 impacts include $\mathrm{S}_{2}, \mathrm{CS}_{2}, \mathrm{CS}, \mathrm{OCS}, \mathrm{NH}_{3}, \mathrm{HCN}$, $\mathrm{C}_{2} \mathrm{H}_{4}, \mathrm{H}_{2} \mathrm{O}, \mathrm{CO}$, and possibly $\mathrm{H}_{2} \mathrm{~S}$ (see Lellouch 1996). Of these observed species, $\mathrm{S}_{2}$, OCS, $\mathrm{H}_{2} \mathrm{~S}$, and $\mathrm{NH}_{3}$ are found to be transient-observations taken months (and in some cases, days) after the impacts demonstrate that these molecules have disappeared or have been substantially reduced after the impacts (Noll et al. 1995, Yelle \& McGrath 1996, Lellouch et al. 1995, Bézard et al. 1995, Griffith et al. 1995b, Fast et al. 1995). The signatures of two other molecules, $\mathrm{CS}_{2}$ and $\mathrm{CO}$, are observed to weaken over time, but spectra taken $\sim 1$ year after the impacts show evidence for the continued existence of both $\mathrm{CS}_{2}$ and CO in the jovian stratosphere (McGrath et al. 1995, Matthews et al. 1995, 
R. Moreno et al. 1995). In contrast, spectral signatures for HCN and CS remain strong throughout the year following the impacts, indicating that the CS and HCN abundances have remained constant or even increased with time ( $R$. Moreno et al. 1995, Matthews et al. 1995).

In the following sections, we describe how photochemical models can be used to simulate the evolution of these and other vapor-phase species at the impact sites; in particular, we recount the details of the photochemical models of Moses et al. (1995a,b,c). Because the models rely on accurate descriptions of the chemical state of the atmosphere just after the impacts, we also delve briefly into the details of some of the observations and theoretical predictions regarding the impact chemistry. More thorough discussions are presented in other chapters in this volume: observational results are reviewed by Lellouch (1996), and thermochemical models are described by Zahnle (1996). We then discuss the important photochemical reactions that control the abundances of the major observed species and compare model predictions with observational data.

\section{Photochemical model: Initial conditions}

Without accurate initial conditions, photochemical models cannot present a reasonable description of the time variation of the chemistry at the impact sites. Fortunately, observational coverage of the impact events was extensive. Unfortunately, complete spectral, temporal, and spatial coverage of each impact site was impossible. Different observations refer to different impact sites at different times and are sensitive to different altitudes; these issues must be considered carefully before initial chemical profiles can be developed. In addition, the impact and plume re-entry mechanics were complicated-different regions of the impact sites map back to diverse temperature and compositional regimes in the impact plume/fireball and hence probably contain different final compositions. Theoretical thermochemical models can help shed light on these issues, but they, too, are hampered by a lack of knowledge of physical and chemical conditions in the fireball and plume stages.

Moses et al. $(1995 \mathrm{a}, \mathrm{b}, \mathrm{c})$ have attempted to consider some of these complexities by splitting the photochemical modeling into two parts. First, Moses et al. (1995a,b) have created a model designed to reproduce the photochemical evolution in the dark central core region of an impact site (e.g., a region that may contain fewer molecules derived from the comet). Then, (Moses et al. 1995c) have created a model designed to be more representative of extended regions of the impact sites, or the impact sites as a whole. The most obvious difference between the two models is that the dark-core model assumes a very low abundance of oxygen species while the whole-region model assumes a much higher abundance of oxygen species. As discussed below, the results of this splitting were not entirely satisfactory with regard to the actual situation on Jupiter, and better descriptions of the initial chemical state of the atmosphere at the impact sites should be possible now that more observational analyses are being published.

Table 1 shows the initial conditions assumed in the photochemical models. Column abundances at three different pressure levels are included to aid in comparisons with observations. For the dark-core low-oxygen case (hereafter called Model A), Moses et al. $(1995 \mathrm{a}, \mathrm{b})$ assume that $\mathrm{S}_{2}$ dominates the sulfur compounds, $\mathrm{N}_{2} / \mathrm{NH}_{3} / \mathrm{HCN} \approx$ $10 / 10 / 1.6$, and oxygen compounds are very minor. For the whole-region high-oxygen case (Model $\mathrm{C}$ ), Moses et al. (1995c) assume that most of the oxygen is tied up in CO, with $\left[\mathrm{H}_{2} \mathrm{O}\right] \approx 0.3[\mathrm{CO}],[\mathrm{OCS}] \approx 6 \times 10^{-3}[\mathrm{CO}]$, and minor additional amounts of $\mathrm{SO}_{2}$ and $\mathrm{CO}_{2}$ present. The sulfur and nitrogen abundances are taken from observations, except that $\mathrm{N}_{2}, \mathrm{~S}_{2}$, and $\mathrm{H}_{2} \mathrm{~S}$ are assumed to be present in quantities (perhaps) greater than 


\begin{tabular}{|c|c|c|c|c|c|c|}
\hline \multirow[b]{2}{*}{ Species } & \multicolumn{3}{|c|}{$\begin{array}{c}\text { Model A } \\
\text { Moses et al. }(1995 \mathrm{a}, \mathrm{b})\end{array}$} & \multicolumn{3}{|c|}{$\begin{array}{c}\text { Model C } \\
\text { Moses et al. }(1995 \mathrm{c})\end{array}$} \\
\hline & $\begin{array}{l}\text { above } \\
12 \text { mbar }\end{array}$ & $\begin{array}{l}\text { above } \\
0.11 \mathrm{mbar}\end{array}$ & $\begin{array}{c}\text { above } \\
0.009 \mathrm{mbar}\end{array}$ & $\begin{array}{l}\text { above } \\
12 \text { mbar }\end{array}$ & $\begin{array}{l}\text { above } \\
0.11 \text { mbar }\end{array}$ & $\begin{array}{c}\text { above } \\
0.009 \mathrm{mbar}\end{array}$ \\
\hline$S_{2}$ & $1.5 \times 10^{18}$ & $1.5 \times 10^{17}$ & $1.2 \times 10^{16}$ & $9.4 \times 10^{16}$ & $3.0 \times 10^{16}$ & $2.4 \times 10^{15}$ \\
\hline $\mathrm{H}_{2} \mathrm{~S}$ & $7.7 \times 10^{16}$ & $7.4 \times 10^{15}$ & $6.1 \times 10^{14}$ & $2.0 \times 10^{17}$ & $7.4 \times 10^{15}$ & $6.1 \times 10^{14}$ \\
\hline $\mathrm{CS}$ & $5.4 \times 10^{11}$ & $3.0 \times 10^{10}$ & $2.4 \times 10^{9}$ & $2.2 \times 10^{14}$ & $6.0 \times 10^{13}$ & $4.8 \times 10^{12}$ \\
\hline $\mathrm{CS}_{2}$ & $2.0 \times 10^{15}$ & $1.8 \times 10^{14}$ & $1.5 \times 10^{13}$ & $7.9 \times 10^{14}$ & $2.2 \times 10^{14}$ & $1.8 \times 10^{13}$ \\
\hline $\mathrm{N}_{2}$ & $1.5 \times 10^{17}$ & $1.5 \times 10^{16}$ & $1.2 \times 10^{15}$ & $7.1 \times 10^{16}$ & $2.2 \times 10^{16}$ & $1.8 \times 10^{15}$ \\
\hline $\mathrm{NH}_{3}$ & $1.5 \times 10^{17}$ & $1.5 \times 10^{16}$ & $1.2 \times 10^{15}$ & $3.5 \times 10^{17}$ & $1.2 \times 10^{16}$ & $9.7 \times 10^{14}$ \\
\hline $\mathrm{HCN}$ & $2.4 \times 10^{16}$ & $2.2 \times 10^{15}$ & $1.8 \times 10^{14}$ & $5.0 \times 10^{15}$ & $1.5 \times 10^{15}$ & $1.2 \times 10^{14}$ \\
\hline $\mathrm{H}_{2} \mathrm{O}$ & $1.8 \times 10^{14}$ & $1.5 \times 10^{13}$ & $1.2 \times 10^{12}$ & $1.4 \times 10^{18}$ & $4.5 \times 10^{17}$ & $3.6 \times 10^{16}$ \\
\hline $\mathrm{CO}$ & $1.8 \times 10^{14}$ & $1.5 \times 10^{13}$ & $1.2 \times 10^{12}$ & $4.0 \times 10^{18}$ & $1.3 \times 10^{18}$ & $1.1 \times 10^{17}$ \\
\hline $\mathrm{CO}_{2}$ & $2.3 \times 10^{12}$ & $1.5 \times 10^{11}$ & $1.2 \times 10^{10}$ & $3.8 \times 10^{12}$ & $6.0 \times 10^{11}$ & $4.8 \times 10^{10}$ \\
\hline $\mathrm{SO}_{2}$ & $1.0 \times 10^{13}$ & $7.4 \times 10^{11}$ & $6.1 \times 10^{10}$ & $3.1 \times 10^{13}$ & $7.4 \times 10^{12}$ & $6.0 \times 10^{11}$ \\
\hline OCS & $2.3 \times 10^{12}$ & $1.5 \times 10^{11}$ & $1.2 \times 10^{10}$ & $2.4 \times 10^{16}$ & $7.4 \times 10^{15}$ & $6.1 \times 10^{14}$ \\
\hline
\end{tabular}

TABLE 1. Initial column abundances (molecules $\mathrm{cm}^{-2}$ )

observed, and their abundances are estimated by assuming a comet-like $\mathrm{O} / \mathrm{S} / \mathrm{N}$ ratio of roughly $25 / 2 / 1$ (see Lellouch 1996 ) in the upper stratosphere $(P<0.3$ mbar). Additional amounts of $\mathrm{NH}_{3}$ and $\mathrm{H}_{2} \mathrm{~S}$ are assumed to be present in the lower stratosphere $(P$ $>0.3$ mbar) based on the suggestions of Yelle \& McGrath (1996). Initial conditions for both of these models are out-of-date and need to be updated based on new observational and theoretical analyses.

\subsection{Constraints based on observations}

Moses et al. $(1995 \mathrm{a}, \mathrm{b}, \mathrm{c})$ selected initial abundances for their photochemical models in such a way as to remain as consistent as possible with the available observational reports. A thorough and detailed discussion of the observations is presented in Lellouch (1996). We will not attempt to repeat that information here but will simply provide a summary of some of the sources of the observational constraints. Table 2 contains a list of several early papers that have been particularly useful in constraining initial abundances for the photochemical models. Along with the observed molecules listed in this table, useful upper limits to many additional species are presented by Noll et al. (1995), Lellouch et al. (1995), Atreya et al. (1995), Yelle \& McGrath (1996), Caldwell et al. (1995), and Sprague et al. (1996).

The observations of the chemical species taken at different wavelengths with different instruments are occasionally inconsistent; even within one dataset (e.g., the Hubble Space Telescope ultraviolet spectra), different investigators derive dissimilar results. The inconsistencies probably derive from the different assumptions that have gone into the observational analyses. The major stumbling blocks to deriving chemical abundances are uncertainties about the stratospheric temperatures (for the infrared and even millimeter and sub-millimeter observations) and uncertainties about the absorbing properties of the aerosols (for the ultraviolet observations). However, most of the recent reports appear to exhibit a convergence with regard to chemical abundances (see Lellouch 1996), and it is hoped that these results can be used to place robust constraints on the initial conditions for the photochemical models. 


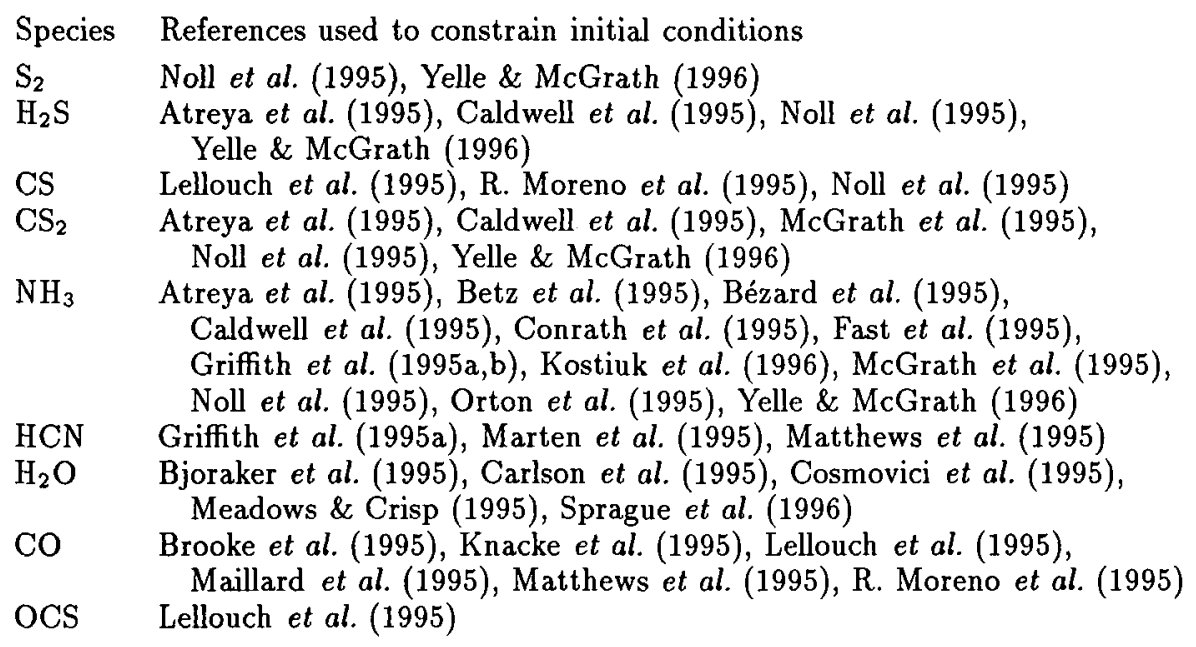

TABLE 2. Sources of observational constraints

\subsection{Constraints based on thermochemical modeling}

When observations are unavailable, uncertain, or contradictory, theoretical models of the thermochemical processing that takes place in the fireball, plume, and plume re-entry shock can be used to help determine the initial chemical composition of the impact sites. Thermochemical models such as those presented by Zahnle (1996), Zahnle et al. (1995), Lyons \& Kansal (1996), and Borunov et al. (1995) that predict how the different elements are partitioned among their constituent molecules are particularly useful in estimating the abundances of species that are difficult or impossible to observe on Jupiter. For example, molecular nitrogen is not observable in the jovian stratosphere, but theoretical models (e.g., Zahnle 1996, Lyons \& Kansal 1996) predict that it should be a major product under most shock pressure/temperature regimes relevant to the impacts. Similarly, $\mathrm{H}_{2} \mathrm{O}$ is difficult to observe once it has cooled to ambient stratospheric temperatures; therefore, the observed $\mathrm{H}_{2} \mathrm{O}$ abundance (e.g., Bjoraker et al. 1995, Sprague et al. 1996) may represent a lower limit. Because $\mathrm{H}_{2} \mathrm{O}$ photolysis drives the oxygen photochemistry, estimating its initial abundance is important for photochemical models. Thermochemical models are useful not only for supplying the photochemical models with initial conditions, but also for helping to determine the elemental compositions of the comet and/or jovian troposphere and for constraining the physical conditions of the impacts.

The temperatures and pressures in the fireball and re-entry shock play a critical role in determining the chemical makeup at the impact sites (cf. Zahnle 1996, Lyons \& Kansal 1996). Although infrared observations are used to pin down the shock temperatures during plume re-entry (e.g., Kim et al. 1995), the conditions in the initial shock are less certain. Numerical models of the impacts can help with this task. Zahnle (1996) uses hydrodynamic plume models to define the physical conditions for his thermochemical modeling; however, he finds that different gas parcels experience very different thermal histories depending on where they were positioned during the initial shock. Currently, no one has "added up" the different parcels in such a way as to map out compositional changes at the impact sites (due to different shock conditions) so that a three-dimensional description of the impact-site composition can be developed. 
Even more important to the thermochemical models may be the relative elemental abundances in the plume/fireball; in particular, the $\mathrm{C} / \mathrm{O}$ ratio controls much of the thermochemistry. For moderate or high shock temperatures, Zahnle (1996) and Lyons \& Kansal (1996) show that plumes with $\mathrm{C} / \mathrm{O}>1$ allow most of the oxygen to be tied up in $\mathrm{CO}$, with $\mathrm{H}_{2} \mathrm{O}, \mathrm{SO}_{2}, \mathrm{SiO}, \mathrm{NO}$, and $\mathrm{SO}$ playing a minor role; the excess carbon can then be used to form species such as carbon sulfide and hydrocarbons. Plumes with $\mathrm{C} / \mathrm{O}<1$ have $\mathrm{H}_{2} \mathrm{O}$ being more important than in the $\mathrm{C} / \mathrm{O}>1$ case, $\mathrm{C}-\mathrm{S}$ species being minor, and $\mathrm{SO}$ and $\mathrm{SO}_{2}$ becoming increasingly important as shock temperatures become higher. What was the $\mathrm{C} / \mathrm{O}$ ratio in the plumes during the SL9 impacts? That question may not be a reasonable one to ask because different portions of the plume may have contained different elemental compositions due to a variable amount of mixing between the vaporized comet and jovian air. Observations are somewhat contradictory regarding this point. Both $\mathrm{H}_{2} \mathrm{O}$ and OCS were observed in non-trivial quantities, suggesting that $\mathrm{C} / \mathrm{O}<1$. However, $\mathrm{CS}$ and $\mathrm{CS}_{2}$ were also observed in moderate quantities while $\mathrm{SO}_{2}$ is not reported, suggesting that $\mathrm{C} / \mathrm{O}>1$. The problem is clearly complex. We seem to be seeing more than one type of chemistry in different regions of the impact sites. Until model parameter space has been explored more fully and until the observational constraints become increasingly secure, the initial conditions at the impact sites will remain uncertain.

\section{Photochemical model: Other details}

Moses et al. begin their modeling approximately one half hour after the impacts, after the plumes have splashed back down and spread into the upper atmosphere and after the surrounding air has cooled to a significant degree. Thermochemical processes cease to dominate the chemistry at this point, and solar radiation takes over. The models are one-dimensional in the vertical direction. Molecular and eddy diffusion are considered, but horizontal spreading is neglected. Because of this and other oversimplifications, the models are designed to illustrate general trends in the evolutionary behavior of the molecules introduced by the impacts; the results should be regarded as illustrative rather than quantitative.

The photochemical models simulate the variation of 145 different vapor-phase sulfur, nitrogen, oxygen, and hydrocarbon compounds at the impact sites. Over 900 chemical reactions are included. Most of the reaction rates are taken from the NIST Chemical Kinetics Database (version 6.0, Mallard et al. 1994) and literature published within the last couple of years; however, several potentially important reactions used in the model have never been studied in the laboratory. Moses et al. estimated the pathways, rates, and products for these reactions. The sulfur reactions, in particular, are poorly studied. A complete reaction list is available from $\mathrm{J}$. Moses upon request.

The background atmosphere, temperature profile, and diffusion coefficients of Gladstone et al. (1996) are used in the photochemical models. Solar flux values from 1983 data are used in Model C; values from 1980 data, which are probably higher than those relevant to the 1994 impact date, are used in Model A. The exact choice of solar flux does not significantly affect the results because much of the photochemistry is initiated by longer wavelength ultraviolet radiation that does not vary noticeably with the solar cycle. The fluxes are diurnally averaged for $44^{\circ} \mathrm{S}$ latitude using the Jupiter-Sun geometry at the time of the impacts. A steady-state model that just considers hydrocarbon photochemistry is first created to simulate the pre-impact atmosphere. The resulting hydrocarbon-species profiles are then used as initial conditions for the post-impact model. 
For boundary conditions, zero flux is assumed for all species except atomic $\mathrm{H}$ at the top of the atmosphere $\left(10^{-6} \mathrm{mbar}\right)$ and a zero concentration gradient at the bottom ( 6 bar) so that the species flow into the troposphere at a maximum possible rate. Atomic hydrogen, which is produced in the thermosphere of Jupiter, is given a downward flux of $4 \times 10^{9}$ $\mathrm{cm}^{-2} \mathrm{~s}^{-1}$ at the top (see Gladstone et al. 1996). Because the impact-derived species are not being continually replenished in the stratosphere, they will eventually diffuse or rain out into the troposphere. The eddy diffusion time scale at $1 \mathrm{mbar}$ is 5 years for the unperturbed stratosphere but may be shorter at the impact sites if the events stirred up the atmosphere to any degree. Condensation is not included explicitly in the Moses et al. models, but potential condensates are noted.

\section{Photochemical model: Results}

The photochemical models of Moses et al. $(1995 \mathrm{a}, \mathrm{b}, \mathrm{c})$ demonstrate that the post-SL9 jovian stratosphere is a very dynamic place, with chemical abundances changing on time scales ranging from minutes to years. In the following sections, we will discuss the major photochemistry results in terms of the fate of the sulfur-, nitrogen-, and oxygenbearing molecules. Although the initial conditions adopted in these early models are unlikely to be correct from a quantitative standpoint, the qualitative results can be used to illuminate the behavior of several of the observed species and to make predictions concerning the long-term evolution of the major impact-derived molecules. We will also use the models to identify molecular species that are photochemically stable and can be used to trace temperature changes or atmospheric dynamics, to identify molecules that might condense and affect atmospheric haze properties, to identify important as-yetunobserved molecular species, and to use the predicted temporal variation in conjunction with observations to learn more about the unique photochemical processes occurring in the post-SL9 jovian stratosphere.

\subsection{Sulfur}

The photochemistry of sulfur in a reducing atmosphere is poorly understood. Very few rate constants are available in the literature, and Moses et al. were forced to estimate the rates for several important reactions. The best-studied reactions are those of sulfur compounds with sulfur, oxygen, and some hydrocarbon species. Significantly absent are reactions of sulfur species with organic radicals and nitrogen species, and possible formation mechanisms for sulfanes $\left(\mathrm{H}_{2} \mathrm{~S}_{\mathrm{x}}\right)$. Despite uncertainties in reaction rates and initial conditions, one robust conclusion can be surmised from the photochemical models: the ultimate sink for the sulfur compounds is condensed $S_{8}$. Figures 1 and 2 illustrate the time variation in the partitioning of the sulfur compounds in the dark-core (Model A) and whole-disk (Model C) models.

Although many sulfur molecules were detected after the impacts, their relative abundances are not well known due to difficulties with the observational analyses. One very important molecule, both because of its high initial abundance and its low photochemical stability, is diatomic sulfur $\left(\mathrm{S}_{2}\right)$. Because of its short lifetime under laboratory conditions, $S_{2}$ has not been well studied. In the photochemical models, $S_{2}$ is lost due to rapid photolysis in the upper atmosphere and to the formation of larger sulfur molecules in the lower stratosphere. The $\mathrm{S}_{2}(\mathrm{~B}-\mathrm{X})$ band system lies at $240-360 \mathrm{~nm}$ and is clearly observed by the Hubble Space Telescope (HST) Faint-Object Spectrograph (FOS) (Noll et al. 1995, Yelle \& McGrath 1995). At wavelengths shorter than $\sim 278 \mathrm{~nm}$, the $\mathrm{S}_{2}$ dissociates into two ground-state $\left({ }^{3} \mathrm{P}\right)$ sulfur atoms. The diurnally averaged lifetime against photolysis for the $\mathrm{S}_{2}$ molecule at $10^{-3}$ mbar and $44^{\circ} \mathrm{S}$ latitude on Jupiter is $\sim 6$ hours. 


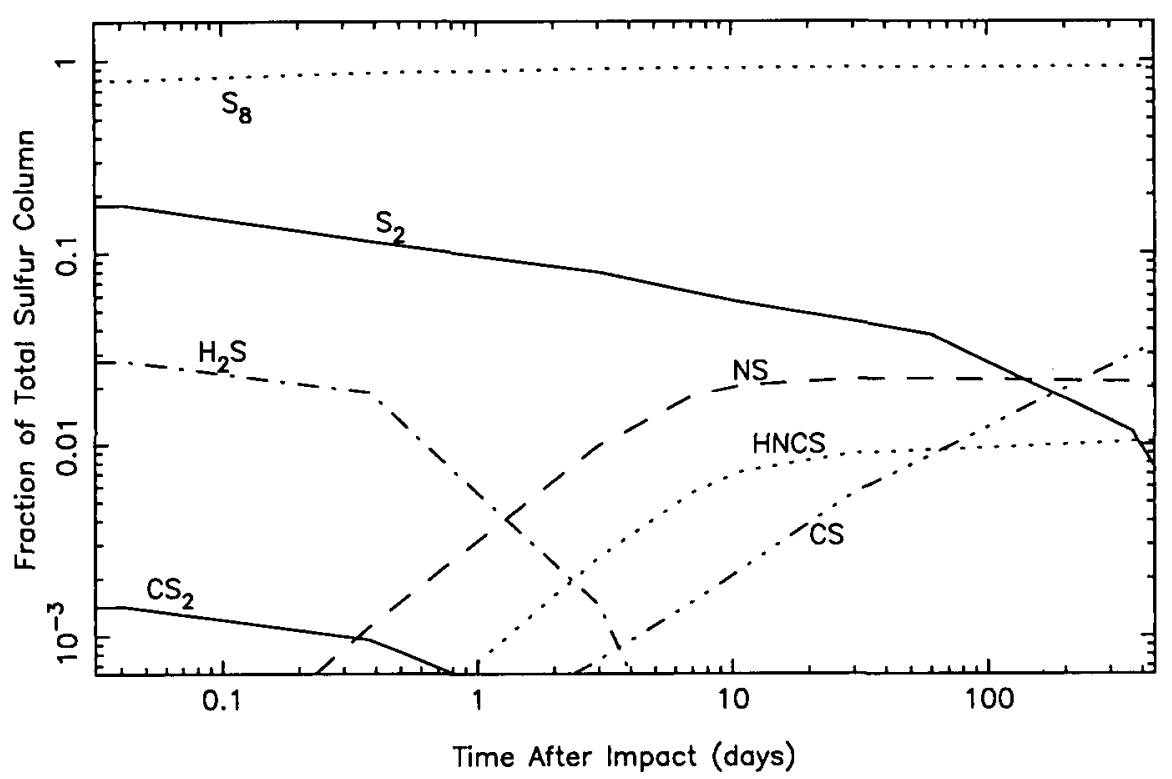

FIGURE 1. The time variation of the partitioning of sulfur compounds in Model A (Moses et al. $1995 \mathrm{a}$ ). The ordinate represents the fraction of the total sulfur column (in terms of $\mathrm{S}$ atoms) that is contributed by the various molecules.

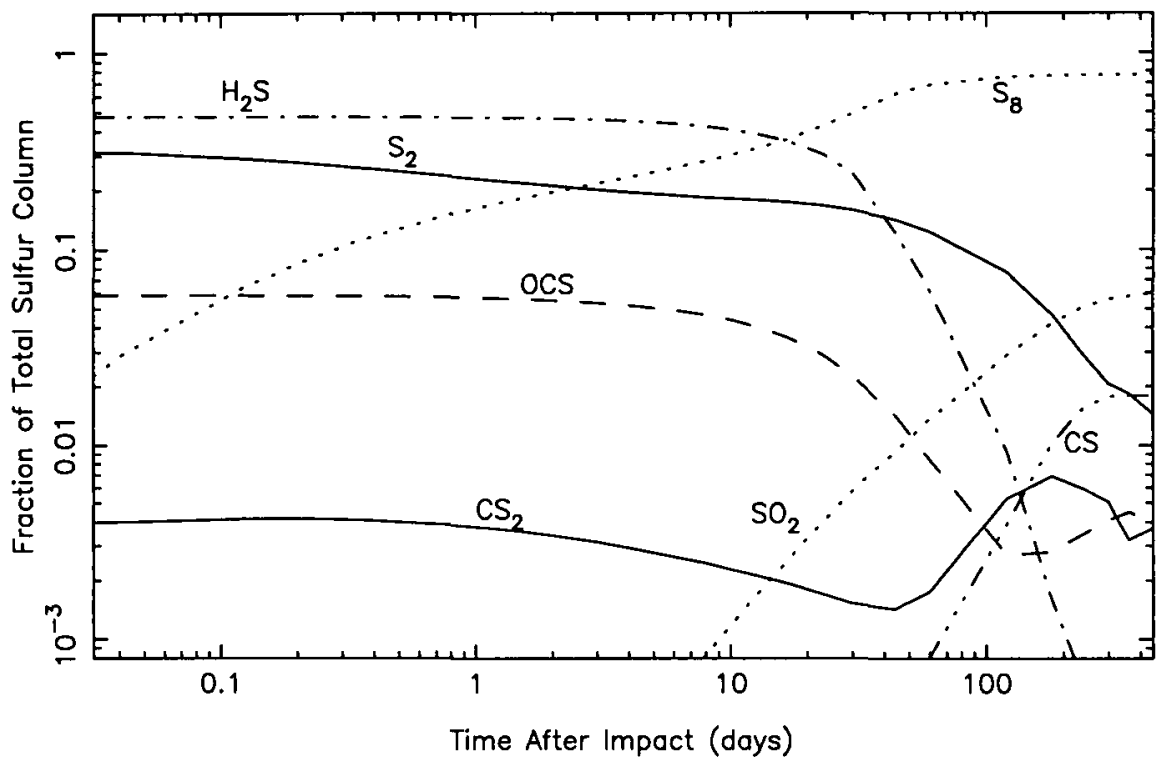

FIgURE 2. The time variation of the partitioning of sulfur compounds in Model C (Moses et al. 1995c). The ordinate represents the fraction of the total sulfur column (in terms of $S$ atoms) that is contributed by the various molecules. Not shown, but also important sulfur reservoirs at various times, are $\mathrm{S}, \mathrm{S}_{3}, \mathrm{~S}_{4}, \mathrm{H}_{2} \mathrm{~S}_{4}, \mathrm{SO},(\mathrm{SO})_{2}, \mathrm{~S}_{2} \mathrm{O}, \mathrm{NS}$, and HNCS. 
Ground-state $\mathrm{S}\left({ }^{3} \mathrm{P}\right)$ atoms do not insert into $\mathrm{H}_{2}$ or alkanes $\left(e . g ., \mathrm{CH}_{4}\right.$ and $\left.\mathrm{C}_{2} \mathrm{H}_{6}\right)$, but they do insert into alkenes (e.g., $\mathrm{C}_{2} \mathrm{H}_{4}$ ) and alkynes (e.g., $\mathrm{C}_{2} \mathrm{H}_{2}$ ) to form ring species that are stable in the former case and transient in the latter case. However, if $\mathrm{S}_{2}$ is as abundant as Yelle \& McGrath (1995) indicate (e.g., $5 \times 10^{15} \mathrm{~cm}^{-2}$ ), the most probable fate of the sulfur atoms is to recycle $S_{2}$. Chemical loss processes other than photolysis dominate the loss of $S_{2}$. The major sink for $S_{2}$ in the photochemical models is the production of molecular sulfur $\left(\mathrm{S}_{8}\right)$ via a variety of three-body and other reactions:

$$
\begin{array}{rlll}
\mathrm{S}_{\mathrm{x}} & \stackrel{h \nu}{\longrightarrow} & \mathrm{S}_{\mathrm{x}-1}+\mathrm{S} & \text { for } \mathrm{x}=2,3,4 \\
2 \mathrm{~S} & \stackrel{\mathrm{M}}{\longrightarrow} & \mathrm{S}_{2} & \\
\mathrm{~S}+\mathrm{S}_{2} & \stackrel{\mathrm{M}}{\longrightarrow} \mathrm{S}_{3} & \\
2 \mathrm{~S}_{3} & \stackrel{\mathrm{M}}{\longrightarrow} & \mathrm{S}_{6} & \\
\mathrm{~S}_{2}+\mathrm{S}_{\mathrm{x}} & \stackrel{\mathrm{M}}{\longrightarrow} & \mathrm{S}_{\mathrm{x}+2} & \text { for } \mathrm{x}=2,4,6 \\
\mathrm{~S}+\mathrm{S}_{\mathrm{x}} & \longrightarrow & \mathrm{S}_{2}+\mathrm{S}_{\mathrm{x}-1} & \text { for } \mathrm{x}=3,4,5,6 \\
2 \mathrm{~S}_{4} & \stackrel{\mathrm{M}}{\longrightarrow} & \mathrm{S}_{8} &
\end{array}
$$

where $\mathrm{M}$ represents any third molecule or atom and $h \nu$ represents an ultraviolet photon. The $\mathrm{S}+\mathrm{S}$ and $\mathrm{S}_{2}+\mathrm{S}_{2}$ three-body reactions have been found to be extremely rapid in the laboratory (e.g., Nicholas et al. 1979); the other three-body rates have not been measured, and Moses et al. conservatively adopt rates that are lower than that for $S_{2}+S_{2}$. Even so, the formation of $S_{8}$ proceeds extremely rapidly in the lower stratosphere. Over $70 \%$ of the initial column budget of $\mathrm{S}_{2}$ molecules in Model $\mathrm{A}$ has been converted to $\mathrm{S}_{8}$ in the first hour of the calculations, and another $\sim 10 \%$ is converted to other sulfur molecules during the same time period. $\mathrm{S}_{8}$ has a low volatility and will condense almost as soon as it is formed.

Because the reaction $2 \mathrm{~S}_{2} \stackrel{\mathrm{M}}{\longrightarrow} \mathrm{S}_{4}$ dominates the loss of $\mathrm{S}_{2}$ in the stratosphere, the rate of loss is dependent on the initial $S_{2}$ abundance. Moses et al. start with 16 times less $\mathrm{S}_{2}$ in Model $\mathrm{C}$ than they do in Model $\mathrm{A}$, so the rate of conversion of $\mathrm{S}_{2}$ to other sulfur molecules in Model $\mathrm{C}$ is much slower (cf. figures $1 \& 2$ ). However, neither model has $\mathrm{S}_{2}$ molecules being lost as quickly as one might expect. Rapid photolysis of $\mathrm{S}_{3}$ and $\mathrm{S}_{4}$ ensures efficient recycling of the $S_{2}$ by the following scheme:

$$
\begin{array}{rll}
2\left(2 \mathrm{~S}_{2}\right. & \stackrel{\mathrm{M}}{\longrightarrow} & \left.\mathrm{S}_{4}\right) \\
\mathrm{S}_{4} & \stackrel{h \nu}{\longrightarrow} & \mathrm{S}_{3}+\mathrm{S} \\
\mathrm{S}_{3} & \stackrel{h \nu}{\longrightarrow} & \mathrm{S}_{2}+\mathrm{S} \\
\mathrm{S}+\mathrm{S}_{3} & \longrightarrow & 2 \mathrm{~S}_{2} \\
\mathrm{~S}+\mathrm{S}_{4} & \longrightarrow & \mathrm{S}_{2}+\mathrm{S}_{3} \\
\hline \multicolumn{2}{c}{\text { Net: nothing }}
\end{array}
$$

This recycling scheme allows $S_{2}$ to persist in the middle stratosphere in the photochemical models despite rapid loss mechanisms. Remember, however, that the Moses et al. models are diurnally averaged. On Jupiter, the situation may be different. Recycling of $\mathrm{S}_{2}$ at the impact sites will be very efficient until the sites rotate beyond the evening terminator. Once photons are no longer available to dissociate the $\mathrm{S}_{2}, \mathrm{~S}_{3}$, and $\mathrm{S}_{4}$ molecules, formation of $\mathrm{S}_{8}$ will proceed uninhibitedly. Therefore, the diurnally averaged models may considerably overestimate the $S_{2}$ abundance after a full Jupiter rotation. Future models should allow diurnal variation. In addition, the $\mathrm{S}_{2}$ may have been deposited higher in the atmosphere and be at a higher temperature (Yelle \& McGrath 1995) than has been assumed in the photochemical models. In that case, the formation of $S_{8}$ and other large sulfur molecules will be inhibited. 


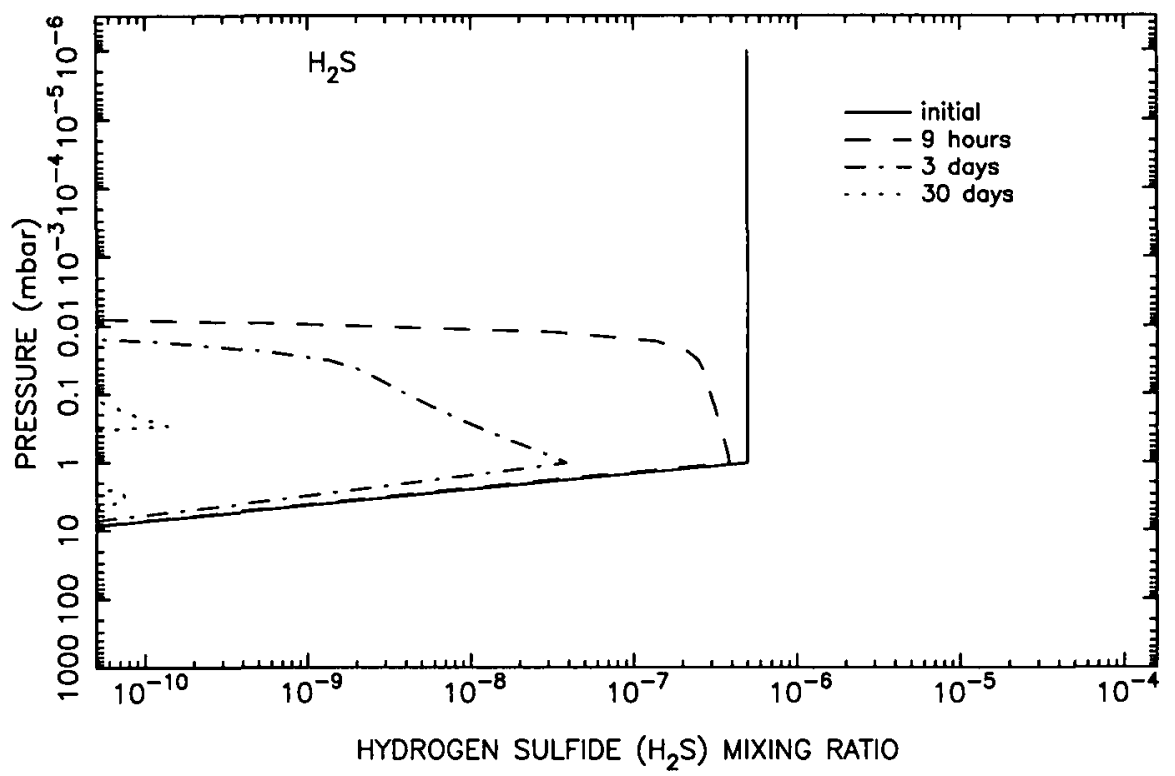

Figure 3. The photochemical evolution of $\mathrm{H}_{2} \mathrm{~S}$ in Model A (from Moses et al. 1995a) in terms of the temporal variation of the $\mathrm{H}_{2} \mathrm{~S}$ mixing ratio profile.

Hydrogen sulfide $\left(\mathrm{H}_{2} \mathrm{~S}\right)$ has been inferred from the July 18 HST FOS spectra of the $\mathrm{G}$ impact site (Noll et al. 1995, Yelle \& McGrath 1996) because of the presence of a broad absorption feature in the $180-210 \mathrm{~nm}$ region. However, this spectral signature is not unique to $\mathrm{H}_{2} \mathrm{~S}$; Atreya et al. (1995) suggest that the absorption slope in this wavelength region is due to aerosols rather than to $\mathrm{H}_{2} \mathrm{~S}$ (although they, too, seem to include $\mathrm{H}_{2} \mathrm{~S}$ in their modeling). There are many reasons why one might expect hydrogen sulfide to be present after the impacts. Thermochemical models (e.g., Zahnle 1996, Lyons \& Kansal 1996) show that $\mathrm{H}_{2} \mathrm{~S}$ tends to form under similar shock temperature and pressure conditions as $\mathrm{NH}_{3}$, and $\mathrm{NH}_{3}$ was observed to be enhanced in the jovian stratosphere after the SL9 impacts. If the comet fragments penetrated to at least the putative $\mathrm{NH}_{4} \mathrm{SH}$ clouds and/or if sulfur was present in the comet in a solar-type abundance, then Zahnle (1996) and Lyons \& Kansal (1996) predict that $\mathrm{H}_{2} \mathrm{~S}$ will be present after the plume splashdown in regions in which plume re-entry temperature did not exceed $2000 \mathrm{~K}$ (e.g., near the central region of the plume re-entry scars). Similarly, if the bulk of the $\mathrm{NH}_{3}$ comes from a later "upwelling" of tropospheric material, as Yelle and McGrath (1996) and others have suggested, then one might also expect $\mathrm{H}_{2} \mathrm{~S}$ to be present along with the $\mathrm{NH}_{3}$. Because of these theoretical predictions, Moses et al. (1995a,b,c) have included $\mathrm{H}_{2} \mathrm{~S}$ in their photochemical models, and have even added "extra" $\mathrm{H}_{2} \mathrm{~S}$ in the lower stratosphere in Model $\mathrm{C}$ based on Yelle \& McGrath's suggestion that the bulk of both the ammonia and hydrogen sulfide may be located at pressures greater than 5 mbar. Because the presence of $\mathrm{H}_{2} \mathrm{~S}$ is not clear-cut, both models may greatly overestimate the initial abundance of hydrogen sulfide.

The photochemical models demonstrate that $\mathrm{H}_{2} \mathrm{~S}$ has a very short lifetime in the jovian stratosphere (see figure 3). The $\mathrm{H}_{2} \mathrm{~S}$ lifetime against photolysis is $\sim 2$ days at $10^{-3} \mathrm{mbar}$. $\mathrm{H}_{2} \mathrm{~S}$ is also lost from the upper atmosphere by reaction with atomic hydrogen; both processes act to remove $\mathrm{H}_{2} \mathrm{~S}$ from the upper atmosphere on time scales of hours. The SH 
formed from the $\mathrm{H}_{2} \mathrm{~S}$ loss processes does not act to recycle the $\mathrm{H}_{2} \mathrm{~S}$. In the middle and upper stratosphere, $\mathrm{H}_{2} \mathrm{~S}$ photochemistry can be reduced to the following simple scheme:

\begin{tabular}{rll}
$\mathrm{H}_{2} \mathrm{~S}$ & $\stackrel{h \nu}{ } \mathrm{SH}+\mathrm{H}$ \\
$\mathrm{H}_{2} \mathrm{~S}+\mathrm{H}$ & $\longrightarrow$ & $\mathrm{SH}+\mathrm{H}_{2}$ \\
$\mathrm{SH}+\mathrm{H}$ & $\longrightarrow$ & $\mathrm{H}_{2}+\mathrm{S}$ \\
$\mathrm{SH}+\mathrm{S}$ & $\longrightarrow \mathrm{S}_{2}+\mathrm{H}$ \\
\hline Net: $2 \mathrm{H}_{2} \mathrm{~S}$ & $\longrightarrow$ & $2 \mathrm{H}_{2}+\mathrm{S}_{2}$
\end{tabular}

The above scheme, which operates rapidly in the jovian stratosphere, shows that the $\mathrm{H}_{2} \mathrm{~S}$ photolysis products act to increase the budget of the elemental sulfur molecules in the atmosphere.

Moses et al. (1995c) find that in Model $\mathrm{C}, \mathrm{H}_{2} \mathrm{~S}$ can persist in the lower stratosphere if $\mathrm{UV}$-absorbing dust is present to act as an effective shield against photolysis. Because $\mathrm{H}_{2} \mathrm{~S}$ photolysis is the primary source of $\mathrm{H}$ atom production at altitudes below $0.1 \mathrm{mbar}$, both loss mechanisms described in the above scheme are inhibited by dust shielding. In both photochemical models, however, the $\mathrm{H}_{2} \mathrm{~S}$ is eventually removed from the stratosphere (cf. figures $1 \& 2$ ).

Hydrogen tetrasulfide $\left(\mathrm{H}_{2} \mathrm{~S}_{4}\right)$ and other sulfanes $\left(\mathrm{H}_{2} \mathrm{~S}_{\mathrm{x}}\right)$ are produced in minor quantities as result of $\mathrm{H}_{2} \mathrm{~S}$ and $\mathrm{S}_{2}$ photolysis. When $\mathrm{SH}$ reacts with sulfur radicals such as $\mathrm{S}_{3}$ and $\mathrm{S}_{4}, \mathrm{HS}_{2}$ is formed. Two $\mathrm{HS}_{2}$ molecules can react along with a stabilizing third molecule or atom to form $\mathrm{H}_{2} \mathrm{~S}_{4}$. However, this process is not the dominant loss mechanism for $\mathrm{HS}_{2}$ in the photochemical models, and $\mathrm{H}_{2} \mathrm{~S}_{4}$ and $\mathrm{H}_{2} \mathrm{~S}_{\mathrm{x}}$ never become very abundant. $\mathrm{H}_{2} \mathrm{~S}_{4}$ and $\mathrm{H}_{2} \mathrm{~S}_{\mathrm{x}}$ are relatively involatile and can condense in the jovian stratosphere.

Carbon disulfide $\left(\mathrm{CS}_{2}\right)$ is observed unambiguously in the HST FOS spectra (Noll et al. 1995, Atreya et al. 1995, Yelle \& McGrath 1996). Both Yelle \& McGrath (1996) and Atreya et al. (1995) derive $\mathrm{CS}_{2}$ column abundances of $\sim 10^{15} \mathrm{~cm}^{-2}$. $\mathrm{CS}_{2}$ has strong (resolved) absorption bands in the $185-230 \mathrm{~nm}$ region. At these wavelengths, the dissociation pathway is $\mathrm{CS}+\mathrm{S}$, with $\sim 80 \%$ of the sulfur atoms being formed in the ${ }^{1} \mathrm{D}$ excited state and the rest in the ${ }^{3} \mathrm{P}$ ground state (Yang et al. 1980). The $\mathrm{S}\left({ }^{1} \mathrm{D}\right)$ will then react with $\mathrm{H}_{2}$ to produce $\mathrm{SH}+\mathrm{H}$ and the $\mathrm{SH}$ reacts to reform $\mathrm{S}$ and $\mathrm{S}_{2}$. $\mathrm{CS}_{2}$, like $\mathrm{S}_{2}$, is recycled in the middle or lower stratosphere and is not lost as fast as its photolysis rate ( $\sim 9$ hours at $10^{-3}$ mbar) would indicate. Instead, the CS produced from $\mathrm{CS}_{2}$ photolysis can react with $\mathrm{S}_{2}$ or $\mathrm{SH}$ to recycle $\mathrm{CS}_{2}$. On the other hand, photolysis is effective at removing $\mathrm{CS}_{2}$ from the upper stratosphere (e.g., $P<10^{-3}$ mbar in Model A or $10^{-2}$ mbar in Model $\mathrm{C}$ ). The late increase in the $\mathrm{CS}_{2}$ abundance shown in figure 2 is due to reactions of sulfur and hydrocarbon radicals (see the CS discussion below).

Carbon monosulfide (CS) is a primary thermochemical product in the plume splashdown if the C/O ratio in the plume is grater than unity (Zahnle 1996, Lyons and Kansal 1996). CS is also produced directly by $\mathrm{CS}_{2}$ photolysis and indirectly by several different reaction schemes whose ultimate source revolves around $S_{2}$. Laboratory studies of CS indicate that it is a short-lived radical that seems to self-polymerize rapidly (Moltzen et al. 1988). However, this polymerization reaction, which is not well understood, seems to require the presence of a container wall or other solid surface. Moses et al. $(1995 \mathrm{a}, \mathrm{b}, \mathrm{c})$ therefore concluded that CS might not polymerize in Jupiter's atmosphere (unless the reactions could somehow take place on aerosol surfaces) and so did not include polymerization schemes for CS. The apparent long lifetime of CS in the jovian stratosphere (R. Moreno et al. 1995) seems to have justified this conclusion.

Although Moses et al. (1995a,b,c) did not begin with much CS in their models, they found that the modeled CS abundance increases dramatically with time. The CS pho- 
tochemistry is complex and difficult to follow, but it appears that reactions of $\mathrm{S}_{2}$ and $\mathrm{S}$ with hydrocarbon radicals are responsible for the delayed increase in abundance shown in figures $1 \& 2$. The greater the initial $S_{2}$ abundance, the more CS that will be produced. Several reaction schemes such as the following contribute to CS production in the months following the impacts:

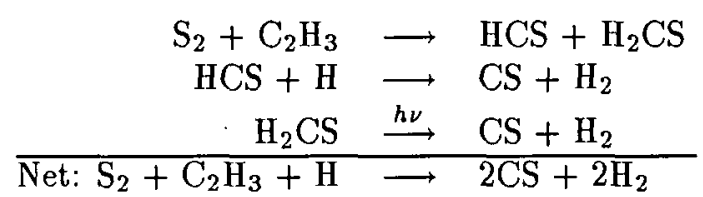

This scheme is the dominant source of CS production in both Model A \& C. A similar scheme involving $\mathrm{S}+\mathrm{CH}_{3} \longrightarrow \mathrm{H}_{2} \mathrm{CS}+\mathrm{H}$ is also important in Model $\mathrm{A}$. The low abundance of $\mathrm{C}_{2} \mathrm{H}_{3}$ and the relatively slow estimated rate for $\mathrm{S}_{2}+\mathrm{C}_{2} \mathrm{H}_{3}$ cause a delay in the production of CS by this and other similar mechanisms, especially in Model C, which has a smaller initial $\mathrm{S}_{2}$ abundance. Note that thioformaldehyde $\left(\mathrm{H}_{2} \mathrm{CS}\right)$ is an important intermediate in most of the schemes that convert $\mathrm{S}$ and $\mathrm{S}_{2}$ into CS and $\mathrm{CS}_{2}$ in the late stages of the sulfur photochemistry. The $\mathrm{H}_{2} \mathrm{CS}$ abundance increases noticeably within a week of so after the impacts in the photochemical models, but its predicted peak column abundance $\left(10^{14}-10^{15} \mathrm{~cm}^{-2}\right)$ may not be sufficient to allow $\mathrm{H}_{2} \mathrm{CS}$ to be observable. Other organo-sulfur molecules such as methyl mercaptan $\left(\mathrm{CH}_{3} \mathrm{SH}\right)$ and ethylene episulfide $\left(\mathrm{C}_{2} \mathrm{H}_{4} \mathrm{~S}\right)$ are predicted to be even less abundant than $\mathrm{H}_{2} \mathrm{CS}$.

Because the limited available laboratory data indicate that CS reactions with other radical species are relatively slow, Moses et al. $(1995 \mathrm{a}, \mathrm{b}, \mathrm{c})$ find that very few reactions seem to be effective at removing CS from Jupiter's stratosphere. The only reactions that permanently remove CS from the modeled atmosphere are the hypothetical reactions $\mathrm{NH}_{2}+\mathrm{CS} \longrightarrow \mathrm{HNCS}+\mathrm{H}$ and $\mathrm{CS}+\mathrm{SO} \longrightarrow \mathrm{S}+\mathrm{OCS}$; all others tend to recycle the CS. Moses et al. estimate relatively small rate constants for both these unmeasured reactions; however, both reactions eventually become important.

Once $\mathrm{NH}_{3}$ photolysis begins, nitrogen-sulfur species become important reservoirs for both sulfur and nitrogen in the photochemical models. This result is highly speculative because very few kinetic studies of reactions between sulfur and nitrogen radicals are available in the literature. The two main nitrogen-sulfur molecules in the photochemical models, nitrogen sulfide (or sulfur nitride, NS) and isothiocyanic acid (HNCS) have both been detected in interstellar space (Turner 1989). Under laboratory conditions on Earth, NS (like CS) is a radical species that tends to polymerize rapidly (Heal 1972). In Jupiter's stratosphere, NS polymerization may not be as important, and photolysis or reactions such as $\mathrm{NH}_{2}+\mathrm{NS} \longrightarrow \mathrm{N}_{2}+\mathrm{H}_{2} \mathrm{~S}$ may be responsible for NS loss. In the photochemical models, $\mathrm{NS}$ is produced by $\mathrm{NH}_{2}+\mathrm{S} \longrightarrow \mathrm{HNS}+\mathrm{S}$ followed by HNS photolysis or HNS + $\mathrm{S} \longrightarrow \mathrm{NS}+\mathrm{SH}$. Photolysis of NS supplies a source of $\mathrm{N}$ atoms to the jovian stratosphere.

As already mentioned, Moses et al. find that HNCS is produced by the reaction of $\mathrm{NH}_{2}$ with CS. Photolysis is the dominant loss mechanism-HNCS has a strong absorption band in the $210-270 \mathrm{~nm}$ region. However, if the dissociation pathway is predominantly $\mathrm{H}+\mathrm{NCS}$, the HNCS is likely to be recycled. Figure 1 shows that the abundances of NS and HNCS increase dramatically with time in Model A; these species also increase with time in Model C, but the NS and HNCS curves were deleted from figure 2 to keep the figure from becoming too confusing.

Carbonyl sulfide (OCS), which was detected at millimeter wavelengths by Lellouch et al. (1995), has a photolysis lifetime of $\sim 24$ days at $10^{-3}$ mbar. The predominant photodissociation pathway is $\mathrm{CO}+\mathrm{S}\left({ }^{1} \mathrm{D}\right)$. Recycling of OCS does not occur in the photochemical models; however, some OCS production takes place by the reaction CS 


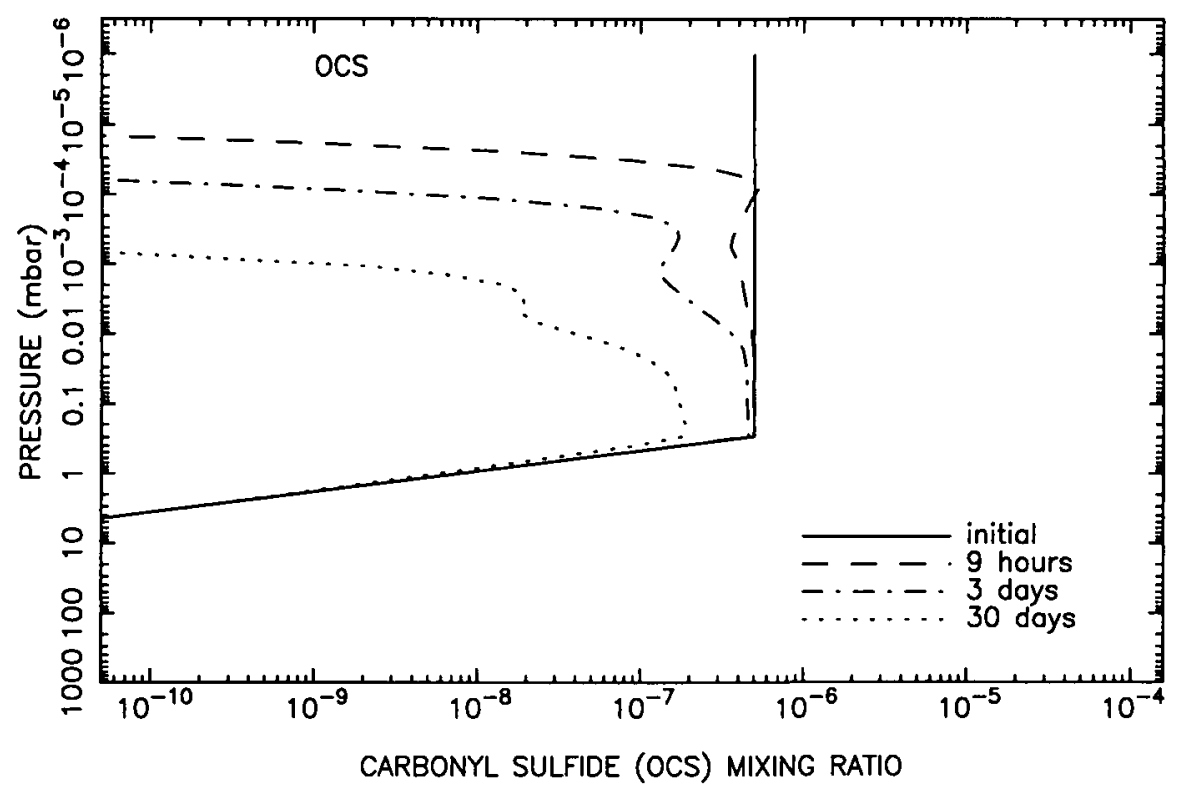

FIGURE 4. The photochemical evolution of OCS in Model C (from Moses et al. 1995c) in terms of the temporal variation of the OCS mixing ration profile.

$+\mathrm{SO} \longrightarrow \mathrm{OCS}+\mathrm{S}$, thus increasing the apparent OCS lifetime. Figure 4 shows the variation of the OCS mixing ratio with time in Model C. Note that OCS is more stable against photolysis in the middle and upper atmosphere than $\mathrm{H}_{2} \mathrm{~S}, \mathrm{CS}_{2}$, or $\mathrm{S}_{2}$.

Sulfur dioxide $\left(\mathrm{SO}_{2}\right)$ and sulfur monoxide $(\mathrm{SO})$ are also important reservoirs for the sulfur in models in which the initial water abundance is high (see figures $2 \& 5$ ). In fact, $\mathrm{SO}_{2}$ is responsible for $5.8 \%$ and $\mathrm{SO}$ for $2.5 \%$ of the total column of sulfur after 1 year in Model C. $\mathrm{SO}$ and $\mathrm{SO}_{2}$ formation depend on $\mathrm{H}_{2} \mathrm{O}$ photolysis. Water photodissociates primarily into $\mathrm{OH}+\mathrm{H}$, and the $\mathrm{OH}$ radicals react with atomic sulfur to form $\mathrm{SO}$, which can then react with itself to form $\mathrm{SO}_{2}+\mathrm{S}$. Although the chemical rate constants and other input parameters to the photochemical models are uncertain, any late build up in the $\mathrm{SO}_{2}$ abundance observed in the jovian stratosphere long after the impacts would most certainly be due to $\mathrm{H}_{2} \mathrm{O}$ photolysis; therefore, a detection or even upper limit on the $\mathrm{SO}_{2}$ abundance many months after the impacts would greatly aid in constraining the water abundance (if the measured $\mathrm{H}_{2} \mathrm{O}$ abundance is indeed a lower limit).

Most of the sulfur molecules produced after the impacts are volatile enough or not abundant enough to condense in the models. Exceptions are $\mathrm{S}_{8}, \mathrm{H}_{2} \mathrm{~S}_{4}$, and other sulfanes $\left(\mathrm{H}_{2} \mathrm{~S}_{\mathrm{x}}\right)$. Elemental sulfur, in particular, should be condensing proliferously about any pre-existing aerosols if $S_{2}$ was at all an important component at the impact sites.

\subsection{Nitrogen}

The kinetics of nitrogen compounds in a reducing atmosphere are much better studied than the corresponding case for sulfur, and Moses et al. $(1995 \mathrm{a}, \mathrm{b}, \mathrm{c})$ were able use laboratory measurements of reaction rates for most of the nitrogen reactions in their model. The nitrogen compounds formed during the SL9 impacts tend to be more stable than the sulfur compounds. In fact, of the three major nitrogen species introduced by the impacts-ammonia $\left(\mathrm{NH}_{3}\right)$, hydrogen cyanide $(\mathrm{HCN})$, and molecular nitrogen $\left(\mathrm{N}_{2}\right)$ only ammonia is photochemically active. Thus, $\mathrm{NH}_{3}$ drives the nitrogen photochemistry 


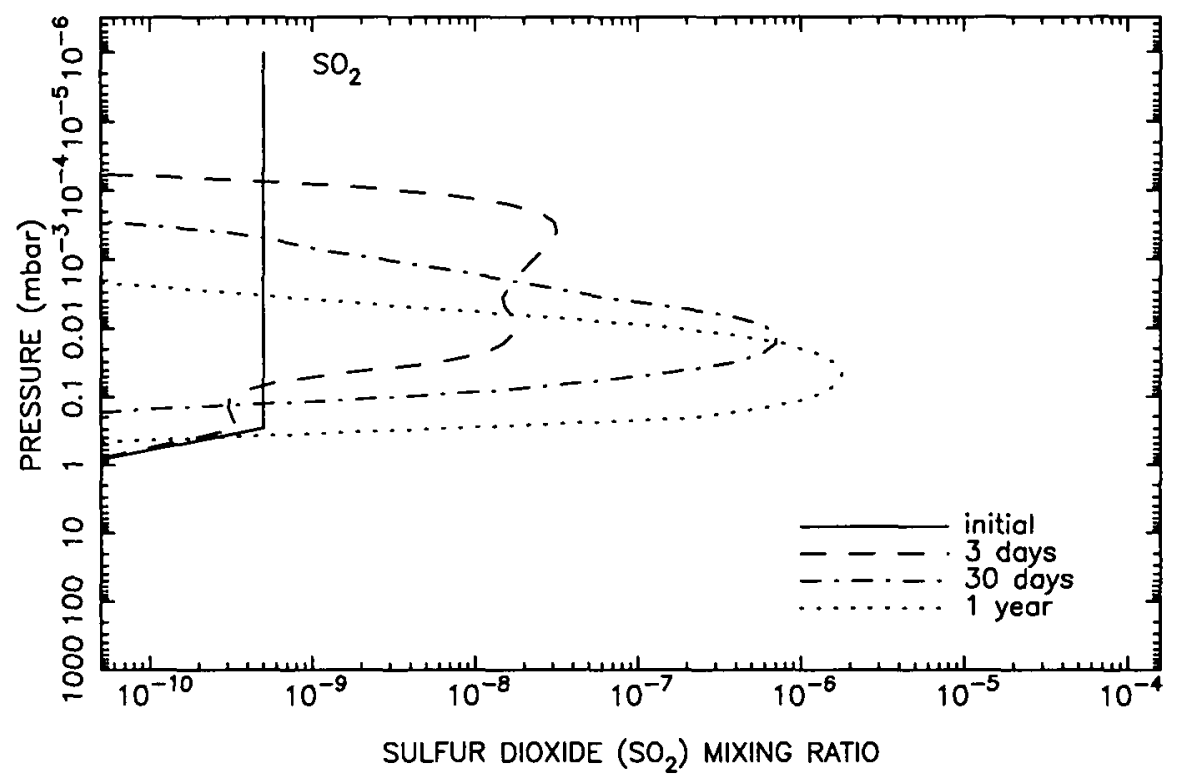

Figure 5. The photochemical evolution of $\mathrm{SO}_{2}$ in Model $\mathrm{C}$ (from Moses et al. 1995c) in terms of the temporal variation of the $\mathrm{SO}_{2}$ mixing ratio profile.

in the post-SL9 jovian stratosphere. Figures $6 \& 7$ illustrate the temporal variation of the partitioning of nitrogen among the different nitrogen compounds. Note that in both models, $\mathrm{N}_{2}$ is the major reservoir for the nitrogen after several months.

The $(\tilde{\mathrm{A}}-\tilde{\mathrm{X}})$ band system of $\mathrm{NH}_{3}$ lies in the $170-220 \mathrm{~nm}$ region. At these wavelengths, the primary photolysis pathway is $\mathrm{NH}_{2}+\mathrm{H}$. The photolysis lifetime of $\mathrm{NH}_{3}$ is $\sim 5.7$ days at $10^{-3} \mathrm{mbar}$ - a time scale considerably longer than that for most of the active sulfur species. In the photochemical models, the $\mathrm{NH}_{2}$ radicals formed by ammonia photolysis react with sulfur radicals such as $\mathrm{S}, \mathrm{SH}, \mathrm{CS}$, and NS to either recycle the ammonia, to form $\mathrm{N}_{2}$ and HCN, or to form nitrogen-sulfur species such as HNS, NS, and HNCS (see Section 4.1). In Model C, NS radicals are allowed to cluster together to form (NS) $)_{2}$ and $(\mathrm{NS})_{4}$, which also become important reservoirs for the nitrogen and sulfur (see figure 7 ). The reactions of $\mathrm{NH}_{2}$ with sulfur radicals cause the ammonia to be recycled less efficiently than otherwise might be the case and cause hydrazine $\left(\mathrm{N}_{2} \mathrm{H}_{4}\right)$ formation to be suppressed.

As mentioned in the previous section, all these proposed sulfur-nitrogen reactions are hypothetical; none have been studied in the laboratory. Searches for pótentially important species such as NS and HNCS at ultraviolet through microwave wavelengths (or even quoted upper limits) would greatly help in distinguishing between several possible pathways in the ammonia photochemistry. Note that these species take days or weeks to build up into potentially observable quantities. Failing such direct observational constraints, the observed lifetime of the $\mathrm{NH}_{3}$ at the impact sites might help determine whether such proposed reactions are occurring.

One very noticeable difference between Models $\mathrm{A} \& \mathrm{C}$ is the apparent lifetime of $\mathrm{NH}_{3}$ in the middle and lower stratosphere (cf. figures $6 \& 7$ ). The greater $\mathrm{NH}_{3}$ lifetime in Model $\mathrm{C}$ has nothing to do with the increased abundance of oxygen compounds in that model; instead, the culprit is increased shielding by other molecules and, more importantly, by dust. Both $\mathrm{CS}_{2}$ and $\mathrm{H}_{2} \mathrm{~S}$ absorb in the same wavelength region as $\mathrm{NH}_{3}$. $\mathrm{CS}_{2}$ is not abundant enough to markedly affect ammonia photolysis. If $\mathrm{H}_{2} \mathrm{~S}$ and $\mathrm{NH}_{3}$ are 


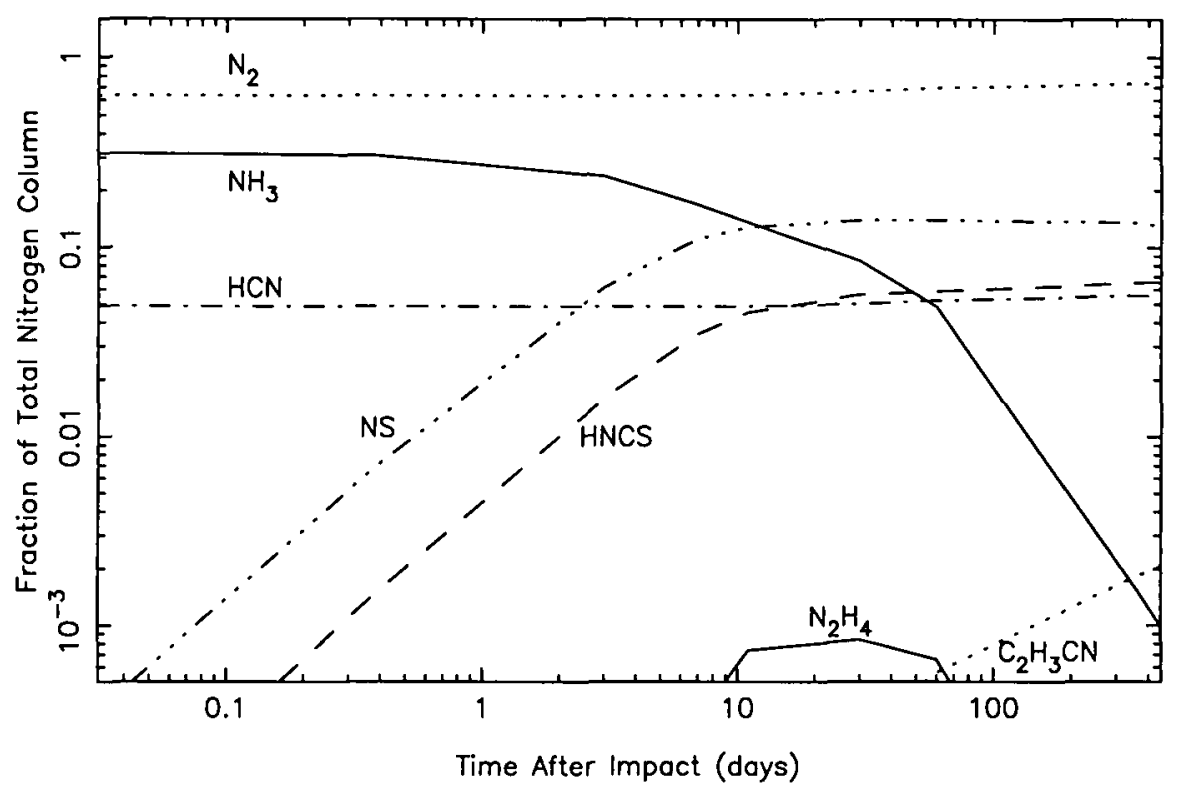

FIgURE 6. The time variation of the partitioning of nitrogen compounds in Model A (Moses et al. 1995b). The ordinate represents the fraction of the total nitrogen column (in terms of $\mathrm{N}$ atoms) that is contributed by the various molecules.

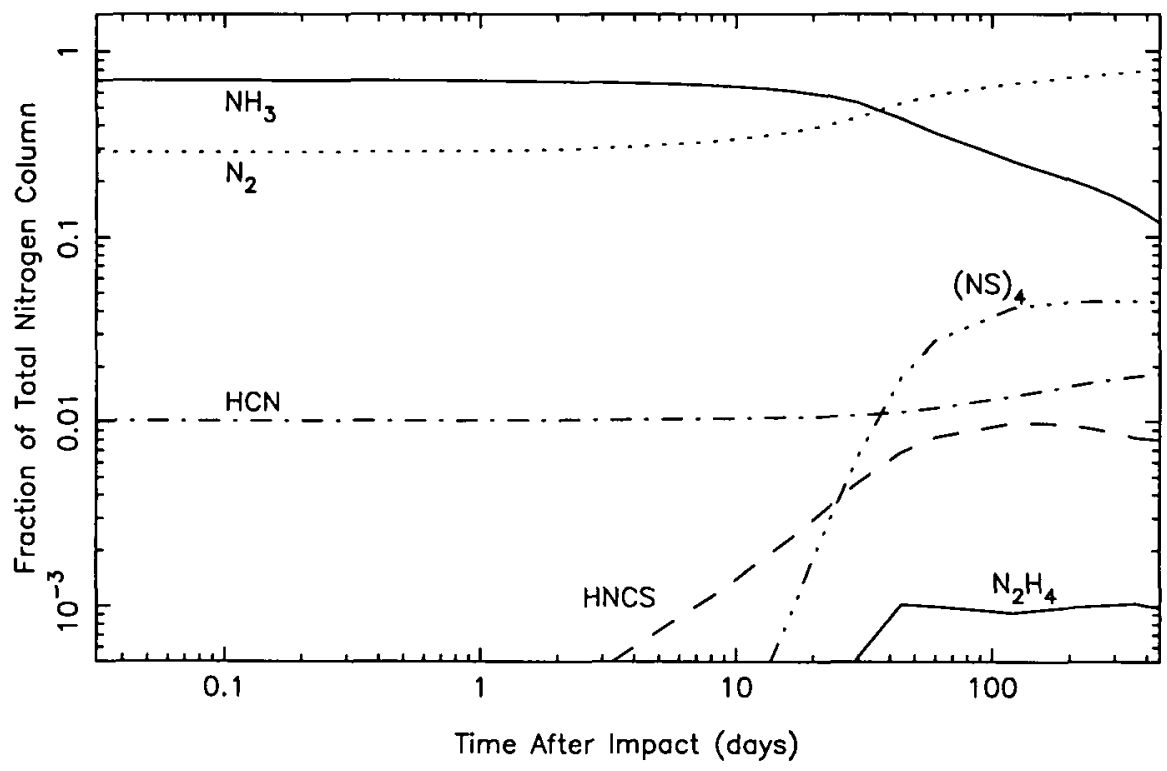

Figure 7. The time variation of the partitioning of nitrogen compounds in Model C (Moses et al. 1995c). The ordinate represents the fraction of the total nitrogen column (in terms of $\mathrm{N}$ atoms) that is contributed by the various molecules. 


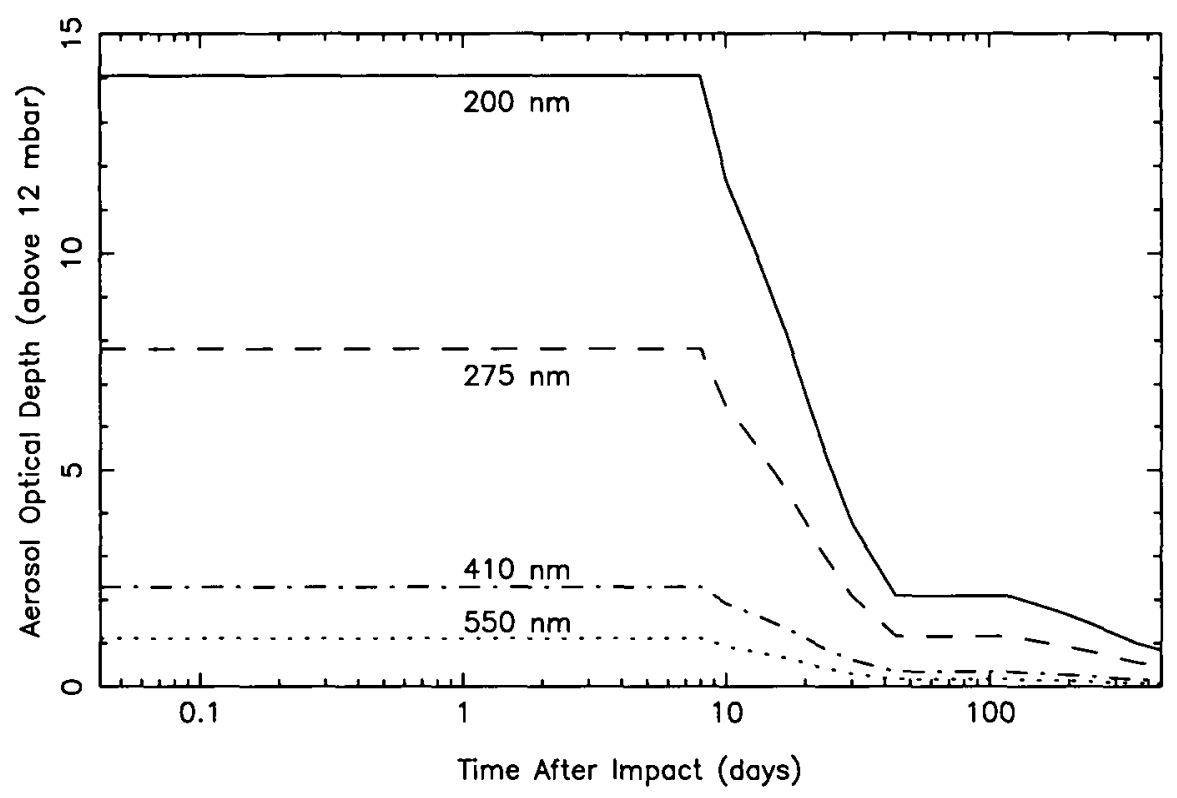

FIGURE 8. Time variation of aerosol opacity in Model C (Moses et al. 1995c)

co-located, as Yelle \& McGrath (1996) suggest, then $\mathrm{H}_{2} \mathrm{~S}$ could be a potentially effective UV shield as long as the $\mathrm{H}_{2} \mathrm{~S}$ persists in the lower stratosphere. The dark widespread dust observed at the impact sites (e.g., West et al. 1995) might also inhibit the penetration of ultraviolet radiation into the lower stratosphere. Several studies of the aerosol debris generated by the impacts suggest that the dust extends up to at least 0.3 mbar or perhaps even higher (e.g., West et al. 1995, Mallama et al. 1995). If so, then this debris could affect ammonia photolysis.

To determine the effect of dust on the photochemistry, Moses et al. (1995c) add aerosol extinction to Model $\mathrm{C}$ and use a Mie scattering code to estimate dust opacities. The dust absorption cross sections are derived by assuming a log-normal distribution of spherical particles with a distribution width of 1.2 and a mean radius of $0.15 \mu \mathrm{m}$ (the radius was chosen to be consistent with the dust analysis of F. Moreno et al. 1995 and Ortiz et al. 1995). The particle imaginary index of refraction was assumed to be typical of outer planetary hazes; i.e., $k=\exp [-2.1-6.5 * \lambda(\mu \mathrm{m})]$ and is consistent with the derived ultraviolet imaginary refractive indices of West et al. (1995). The dust number densities were chosen so that the haze opacity remains approximately consistent with the West et al. UV-visible optical depths. The initial dust profile adopted in Model C has a constant dust density of $\sim 8 \times 10^{3}$ particles $\mathrm{cm}^{-3}$ below $10 \mathrm{mbar}$, a dust number mixing ratio of $1.8 \times 10^{-14}$ between $10^{-10^{-2}} \mathrm{mbar}$ and $10^{-25}$ above $10^{-2} \mathrm{mbar}$. Since West et al. (1995) demonstrate that the dust opacity decreases with time, Moses et al. (1995c) allow the dust number density to be reduced over time; however, the reduction in haze abundance was instituted somewhat arbitrarily. The resulting time variation in the haze opacity is shown in figure 8 . Although not shown in the figure, the ratio of the dust opacities at 275 and $893 \mathrm{~nm}$ derived from this haze model is not quite consistent with the West et al. (1995) results. In addition, the haze model of F. Moreno et al. (1995) and Ortiz et al. (1995) would not be optically thick in the ultraviolet using the optical properties extrapolated from West et al. (1995). Both of these results suggest that the particles are indeed larger than $0.15 \mu \mathrm{m}$ in radius, as indicated by West et al. 


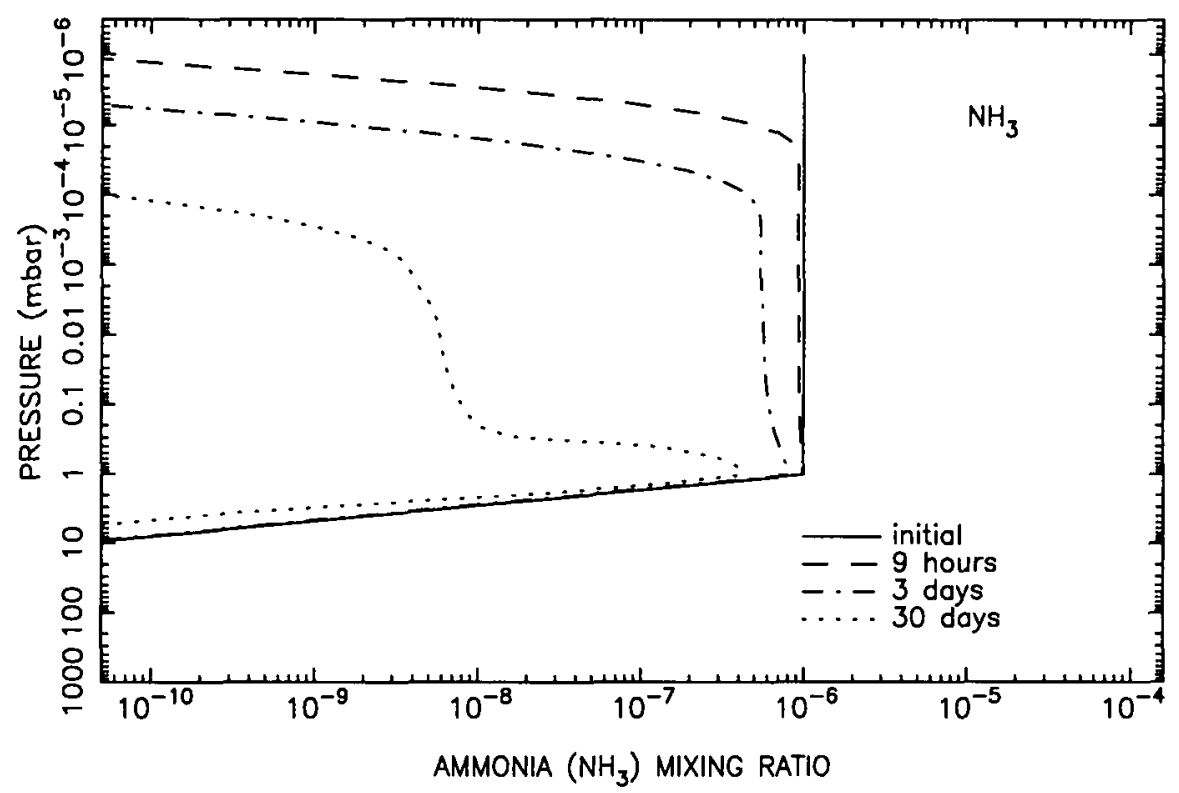

Figure 9. The photochemical evolution of $\mathrm{NH}_{3}$ in Model A (from Moses et al. 1995a) in terms of the temporal variation of the $\mathrm{NH}_{3}$ mixing ratio profile.

Figure 9 illustrates how the $\mathrm{NH}_{3}$ profile varies with time in Model A. In the middle and upper stratosphere $\left(P<10^{-2} \mathrm{mbar}\right)$, the ammonia profile in Model $\mathrm{C}$ is virtually identical to that of Model A. However, absorption of solar radiation by dust keeps more $\mathrm{NH}_{3}$ in the lower stratosphere in Model C. The haze optical depth in Model C is still $\sim 1$ at 1 mbar 10 days after the impacts and remains high for several weeks. Therefore, the dust provides an effective shield for the ammonia at low altitudes and prevents the $\mathrm{NH}_{3}$ from being lost as rapidly as it normally would be. As will be discussed in Section 5, the fact that the $\mathrm{NH}_{3}$ stays in the stratosphere in Model $\mathrm{C}$ much longer than is indicated by the observations suggests that the actual dust deposited by the impacts is not optically thick at millibar pressure levels in the near ultraviolet. Thus, the photochemical models can be used in conjunction with observations to place constraints on the stratospheric aerosol profile.

Hydrogen cyanide does not absorb near-ultraviolet radiation and only absorbs weakly below $190 \mathrm{~nm}$. In addition, no chemical loss mechanisms are effective at removing $\mathrm{HCN}$ from Jupiter's stratosphere. Moses et al. (1995b) find that in Model A, the HCN formed during the plume splashdown is photochemically stable throughout the stratosphere, and they suggest that HCN might therefore be regarded as a good "thermometer" for the stratosphere-changes in the HCN observations might be due to temperature variations or horizontal spreading rather than to changes in total abundance. Moses et al. (1995c) derive a slightly different result for Model $\mathrm{C}$. They see an increase in the $\mathrm{HCN}$ abundance over time due to the following series of reactions: 


\begin{tabular}{rll}
$\mathrm{NH}_{3}$ & $\stackrel{h \nu}{ } \mathrm{NH}_{2}+\mathrm{H}$ \\
$\mathrm{NH}_{2}+\mathrm{S}$ & $\longrightarrow$ & $\mathrm{HNS}+\mathrm{H}$ \\
$\mathrm{HNS}+\mathrm{H}$ & $\longrightarrow \mathrm{H}_{2}+\mathrm{NS}$ \\
$\mathrm{NS}$ & $\stackrel{h \nu}{\mathrm{N}+\mathrm{S}}$ \\
$\mathrm{CH}_{3}+\mathrm{N}$ & $\longrightarrow \mathrm{H}_{2} \mathrm{CN}+\mathrm{H}$ \\
$\mathrm{H}_{2} \mathrm{CN}+\mathrm{H}$ & $\longrightarrow$ & $\mathrm{HCN}+\mathrm{H}_{2}$ \\
\hline Net: $\mathrm{NH}_{3}+\mathrm{CH}_{3}$ & $\longrightarrow \mathrm{HCN}+2 \mathrm{H}_{2}+\mathrm{H}$
\end{tabular}

Because $\mathrm{NH}_{3}$ is initially so much more abundant than $\mathrm{HCN}$ in Model $\mathrm{C}$, and because NS photolysis has been included, the increase in HCN abundance is more noticeable in Model C than in Model A.

Molecular nitrogen was probably an important reservoir for the nitrogen after the impact and the plume re-entry shocks (Zahnle 1996, Lyons \& Kansal 1996). Its presence in the post-SL9 jovian stratosphere is inferred from the fact that the $\mathrm{O} / \mathrm{N}$ ratio of the observed molecules at the impact sites is greater than that of typical comets, suggesting that $\mathrm{N}_{2}$ might make up the "missing" nitrogen component (e.g., Lellouch 1996). $\mathrm{N}_{2}$ has no efficient photochemical loss mechanisms in the jovian stratosphere. The $\mathrm{N}_{2}$ abundance increases with time in the photochemical models due to schemes such as the following:

$$
\begin{array}{rll}
2\left(\mathrm{NH}_{3}\right. & \stackrel{h \nu}{ } & \left.\mathrm{NH}_{2}+\mathrm{H}\right) \\
\mathrm{NH}_{2}+\mathrm{S} & \longrightarrow & \mathrm{HNS}+\mathrm{H} \\
\mathrm{HNS} & \stackrel{h \nu}{\longrightarrow} \mathrm{H}+\mathrm{NS} \\
\mathrm{NH}_{2}+\mathrm{NS} & \longrightarrow & \mathrm{N}_{2}+\mathrm{H}_{2} \mathrm{~S} \\
\hline \text { Net: } 2 \mathrm{NH}_{3}+\mathrm{S} & \longrightarrow & \mathrm{N}_{2}+\mathrm{H}_{2} \mathrm{~S}+4 \mathrm{H}
\end{array}
$$

Moderate amounts of hydrazine $\left(\mathrm{N}_{2} \mathrm{H}_{4}\right)$ and nitriles such as acrylonitrile $\left(\mathrm{C}_{2} \mathrm{H}_{3} \mathrm{CN}\right)$ build up at various times in the photochemical models (see figures $6 \& 7$ ). However, it's not clear that these species can build up in observable quantities.

None of the nitrogen-bearing molecules in the photochemical models are predicted to contribute much mass to the stratospheric aerosol layer. Hydrazine may be abundant enough to condense after several months, and species with uncertain vapor pressures such as (NS) $)_{x}$ clusters or rings may also condense in the stratosphere. If ammonia is as abundant initially in the deep stratosphere as is assumed in Model $\mathrm{C}$, then $\mathrm{NH}_{3}$ is close to its saturation vapor curve in the lower stratosphere, but there are indications that the initial $\mathrm{NH}_{3}$ abundance in Model $\mathrm{C}$ may be an overestimate (see Section 5).

\subsection{Oxygen}

Interest in the chemistry of the Earth's stratosphere has motivated many laboratory studies of oxygen photochemistry, and most of the rate constants for the oxygen reactions in the Moses et al. models are well known. Initial conditions for the oxygen compounds at the impact sites are less certain; $\mathrm{CO}, \mathrm{H}_{2} \mathrm{O}$, and OCS are the only oxygen-bearing molecules that have been identified. Figure 10 illustrates how these and other potentially important oxygen compounds vary with time. Note that $\mathrm{CO}$ and $\mathrm{H}_{2} \mathrm{O}$ are much more photochemically stable than most of the sulfur-bearing molecules or ammonia. Since Model $\mathrm{C}$ is the only one that contains a non-trivial initial amount of water, it will be the focus of our discussion in this section.

Water photolysis drives the oxygen photochemistry. Photolysis of $\mathrm{H}_{2} \mathrm{O}$ occurs at short wavelengths (e.g., $\lambda<190 \mathrm{~nm}$ ); thus, $\mathrm{H}_{2} \mathrm{O}$ is relatively stable in Jupiter's stratosphere. Its photolysis lifetime is almost 3 months at $10^{-3}$ mbar in Model $\mathrm{C}$. In addition, $\mathrm{H}_{2} \mathrm{O}$ is recycled to a large degree once it is photolyzed. The $\mathrm{OH}$ reacts with $\mathrm{H}_{2}$ to reform water. However, some of the $\mathrm{OH}$ radicals react with $\mathrm{S}$ to form $\mathrm{SO}$ or react with $\mathrm{SO}$ to form 


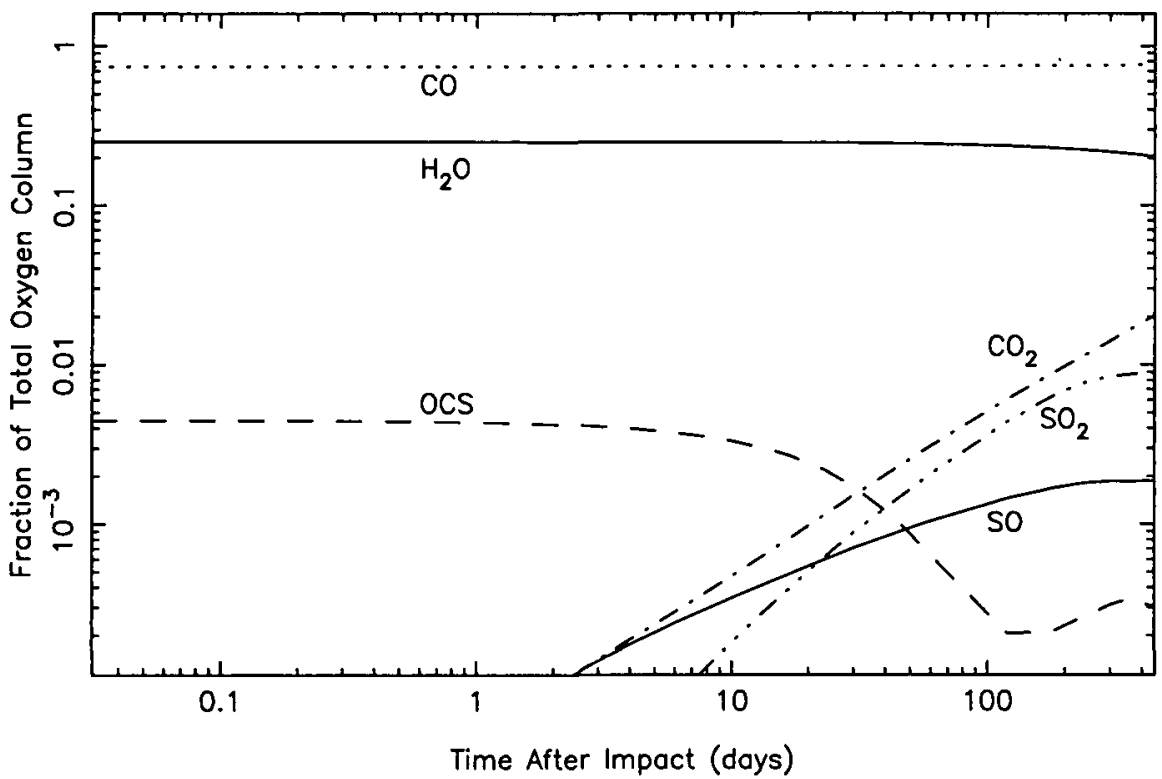

Figure 10. The time variation of the partitioning of oxygen compounds in Model $\mathrm{C}$ (Moses et al. 1995c). The ordinate represents the fraction of the total oxygen column (in terms of $\mathrm{O}$ atoms) that is contributed by the various molecules.

$\mathrm{SO}_{2}$ so that the abundances of sulfur monoxide and sulfur dioxide increase with time. Another interesting loss process is $\mathrm{OH}+\mathrm{CO} \longrightarrow \mathrm{CO}_{2}+\mathrm{H}$. This reaction is slow and barely makes a dent in the $\mathrm{CO}$ abundance after 1 year; however, the reaction does cause the carbon dioxide $\left(\mathrm{CO}_{2}\right)$ abundance to increase noticeably with time (see figure 10).

Theoretical models predict that large quantities of $\mathrm{CO}$ will form during both the initial impact explosion and the plume splashdown for virtually all possible composition, temperature, and pressure conditions assumed for the shocks (Zahnle 1996, Lyons \& Kansal 1996). Carbon monoxide is photochemically stable, and Moses et al. $(1995 \mathrm{a}, \mathrm{b}, \mathrm{c})$ suggest that $\mathrm{CO}$ might be a good tracer for temperature changes or atmospheric dynamics after the impacts. In the photochemical models, $\mathrm{CO}$ is the ultimate repository for most of the oxygen compounds. For instance, $\mathrm{CO}$ is produced directly by $\mathrm{OCS}$ and $\mathrm{CO}_{2}$ photolysis, and indirectly by $\mathrm{H}_{2} \mathrm{O}, \mathrm{SO}$, and $\mathrm{SO}_{2}$ photolysis. Schemes such as the following are effective at converting $\mathrm{H}_{2} \mathrm{O}$ to $\mathrm{CO}$ :

$$
\begin{array}{rll}
\mathrm{H}_{2} \mathrm{O} & \stackrel{h \nu}{ } & \mathrm{OH}+\mathrm{H} \\
\mathrm{OH}+\mathrm{S} & \longrightarrow & \mathrm{SO}+\mathrm{H} \\
\mathrm{SO} & \stackrel{h \nu}{ } \mathrm{S}+\mathrm{O} \\
\mathrm{O}+\mathrm{CH}_{3} & \longrightarrow & \mathrm{H}_{2} \mathrm{CO}+\mathrm{H} \\
\mathrm{H}_{2} \mathrm{CO}+\mathrm{H} & \longrightarrow & \mathrm{HCO}+\mathrm{H}_{2} \\
\mathrm{HCO}+\mathrm{H} & \longrightarrow & \mathrm{CO}+\mathrm{H}_{2} \\
\hline \text { Net: } \mathrm{H}_{2} \mathrm{O}+\mathrm{CH}_{3} & \longrightarrow & \mathrm{CO}+2 \mathrm{H}_{2}+\mathrm{H}
\end{array}
$$

Note that formaldehyde $\left(\mathrm{H}_{2} \mathrm{CO}\right)$ is an intermediary in the above reaction. Moderate amounts (e.g., $10^{13}-10^{15}$ molecules $\mathrm{cm}^{-2}$ ) of $\mathrm{H}_{2} \mathrm{CO}$, methanol $\left(\mathrm{CH}_{3} \mathrm{OH}\right)$, and nitric oxide (NO) form in the photochemical model after a week or so. Other important oxygenbearing molecules include $\mathrm{OCS}, \mathrm{SO}, \mathrm{SO}_{2}$, and $(\mathrm{SO})_{2}$. A discussion of the photochemistry of these molecules is included in Section 4.1. 
None of the oxygen compounds are expected to be abundant enough to condense in the lower stratosphere. It is interesting to note, however, that the initial $\mathrm{H}_{2} \mathrm{O}$ abundance selected for Model $\mathrm{C}$ puts $\mathrm{H}_{2} \mathrm{O}$ very close to its saturation point in the lower stratosphere. No other oxygen compounds in the model are even close to saturation within a period of 15 months after the impacts.

\section{Model-data comparisons}

To determine if the chemical state of the atmosphere has responded as expected to the impacts, we compare the photochemical model predictions with observational data. The record of the time variation of the different observed molecules is particularly useful in determining physical and chemical conditions at the impact sites and in helping to constrain some of the uncertain initial conditions and chemical reaction schemes. Information about the temporal variation of at least 7 of the observed molecules (e.g., $\mathrm{S}_{2}$, $\mathrm{CS}_{2}, \mathrm{CS}, \mathrm{OCS}, \mathrm{NH}_{3}, \mathrm{HCN}, \mathrm{CO}$, and perhaps $\mathrm{H}_{2} \mathrm{~S}$ ) has been presented in the literature. We will discuss each of these molecules and evaluate whether the photochemical models are consistent with the observations. Remember that the photochemical models are one-dimensional; because horizontal spreading is ignored, the models should always overpredict column abundances at later times.

As discussed by Noll et al. (1995), $\mathrm{S}_{2}$ absorption lines were seen in the HST FOS spectra of the $G$ impact site on July 18, 1994 ( 3.5 hours after the G impact) and on July 21,1994 ( $\sim 3$ days after the $G$ impact, but only 45 minutes after the nearby $\mathrm{S}$ impact). The viewing geometry of the observations was not the same in the two cases, and the $S_{2}$ signature in the July 21 spectra may be due to $S_{2}$ at the $G$ impact site, or it may be due to $\mathrm{S}_{2}$ at the smaller, but more recent, $\mathrm{S}$ impact site. No $\mathrm{S}_{2}$ absorption lines were observed on August 9, 1994 (22 days later) or at any time after July 21, 1994 (Noll et al. 1995, McGrath et al. 1995).

In the Moses et al. (1995a) photochemical model (Model A), the $\mathrm{S}_{2}$ abundance drops by a factor of $\sim 20$ in the first month after the impacts; however, most of that reduction occurs in the first day. (Note that the $\mathrm{S}_{8}$ shown in figures $1 \& 2$ is directly derived from $S_{2}$ ). Between 3 days and 30 days, the $S_{2}$ column decreases by only a factor of $\sim 2$. If the July 21 signature is due to the presence of $S_{2}$ at the fresh $S$ site rather than at the 3-day-old $\mathrm{G}$ site, then Model A may be consistent with observations. On the other hand, if the July 21 signature is due to $S_{2}$ at the $G$ impact site, then Model A probably overpredicts the rate of loss of $S_{2}$ at the impact sites.

A straightforward decrease in the assumed initial $S_{2}$ abundance at all altitudes in the photochemical model allows the $\mathrm{S}_{2}$ to remain in the stratosphere for a longer period of time. However, in that situation, the $S_{2}$ probably persists too long to account for observations. For instance, in Model $\mathrm{C}$, the $\mathrm{S}_{2}$ column drops by only a factor of $\sim 3$ in the first 23 days. Although no upper limits are given in Noll et al. (1995) or McGrath et al. (1995) for the August 9, 1994 data, the observations probably indicate a more dramatic decrease in the $\mathrm{S}_{2}$ abundance than is seen in Model $\mathrm{C}$.

A cautionary note needs to be inserted here with regard to the photochemical modeling of $S_{2}$. The $S_{2}$ may initially be confined to higher altitudes than is assumed in the photochemical models (see Yelle \& McGrath 1995), and the photochemistry of $\mathrm{S}_{2}$ is not well understood. More importantly, the photochemical models are diurnally averaged. $\mathrm{S}_{2}$ and the other sulfur radicals have short photochemical lifetimes, and diurnally averaged models may not truly represent the situation at the impact sites. Further comparisons between $\mathrm{S}_{2}$ observations and models should be delayed until more appropriate photochemical models are developed. 
$\mathrm{CS}_{2}$ is always seen in ultraviolet spectra of the impact sites, even 9 months after the impacts (McGrath et al. 1995). This result is consistent with both of the photochemical models of Moses et al. who find that reactions between sulfur and hydrocarbon radicals produce $\mathrm{CS}_{2}$ in the mid-to-lower stratosphere several months after the impacts. Both Model $\mathrm{A}$ and $\mathrm{C}$ predict that $\mathrm{CS}_{2}$ will be readily photolyzed and lost from the upper atmosphere; however, a slower rate of decline in the total $\mathrm{CS}_{2}$ column is predicted in Model $\mathrm{C}$ relative to Model A. Model A exhibits a total drop in the $\mathrm{CS}_{2}$ column of a factor of 40 in the first 30 days while Model $\mathrm{C}$ predicts that the $\mathrm{CS}_{2}$ column would have decreased by a factor of 2.5 between the July 18 and the August 9 observations and by just a factor of $\sim 3$ between July 18 and August 23, 1994. The actual observations seem consistent with the Model $\mathrm{C}$ results but inconsistent with the Model A results. Yelle \& McGrath (1996) derive a decrease in the $\mathrm{CS}_{2}$ column of a factor of 2-3 between July 18 and August 9 , and another factor of $\sim 2$ between August 9 and August 23. The persistence of $\mathrm{CS}_{2}$ in the observations suggests that some shielding is going on (e.g., from dust or from $\mathrm{NH}_{3}$ ) as in Model $\mathrm{C}$ or that $\mathrm{CS}_{2}$ is more efficiently recycled or produced than is evident in Model $\mathrm{A}$.

One interesting prediction from Model $\mathrm{C}$ is that the $\mathrm{CS}_{2}$ will end up being co-located with the stratospheric $\mathrm{NH}_{3}$ weeks or months after the impacts. Yelle \& McGrath (1996) suggest that the bulk of the $\mathrm{CS}_{2}$ is originally located at higher altitudes than the ammonia. However, Moses et al. find that $\mathrm{CS}_{2}$ disappears from the upper stratosphere over time but persists in a similar altitude region as the $\mathrm{NH}_{3}$. It will be interesting to see whether an analysis of the FOS spectra taken in August, 1994 will support this prediction.

CS has been monitored on a regular basis at millimeter and submillimeter wavelengths from the IRAM and JCMT telescopes (Lellouch et al. 1995, R. Moreno et al. 1995, Matthews et al. 1995). Six to twelve months after the impacts, the CS column abundance appears to be $\sim 10$ times less than in July 1994 (Moreno et al. 1995, Matthews et al. 1995, Lellouch 1996). If we follow the arguments of Lellouch (1996) and assume that the spots have spread by a factor of $\sim 80$ in area in this time, then the data imply that the total CS mass may have increased by a factor of $\sim 8$ during the 6-12 month period following the impacts.

Both Models $\mathrm{A}$ and $\mathrm{C}$ exhibit a steady increase in the CS column abundance in the weeks and months following the impacts. In Model A, a factor of 20 increase in the CS column is predicted between 1 week and 1 year after the impacts. In Model C, a factor of 80 increase is predicted between 1 week and 1 year. Both models grossly overestimate the increase of the CS column with time. Because the CS in the photochemical models is derived from $\mathrm{S}_{2}$ photochemistry, the inconsistencies between models and data suggest that the models overestimate the initial $S_{2} / C S$ ratio. In fact, Moses et al. (1995a,b,c) do not begin with much CS at all (see Table 1), mainly because some of the original thermochemical models (e.g., Zahnle et al. 1995) did not favor CS production and because the initial large $S_{2}$ abundance in Model A allowed a substantial build-up in the CS abundance after a day or so (i.e., large initial amounts of CS were not required to explain the observations). If $S_{2} / C S \lesssim 1$ initially, then the photochemical models would not show such a dramatic increase in the CS abundance with time unless some other sulfur compound is present in much larger quantities than CS.

OCS was detected at mm wavelengths at the IRAM telescope on July 22, 1994 (Lellouch et al. 1995). The detection was not confirmed at the same telescope 1 month later (Lellouch 1996). Photochemical models predict that OCS is lost at a steady rate in the jovian stratosphere due to photolysis at near-ultraviolet wavelengths (with a photolysis lifetime of 24 days). Dust helps shield the OCS from photolysis in the Model C; even 


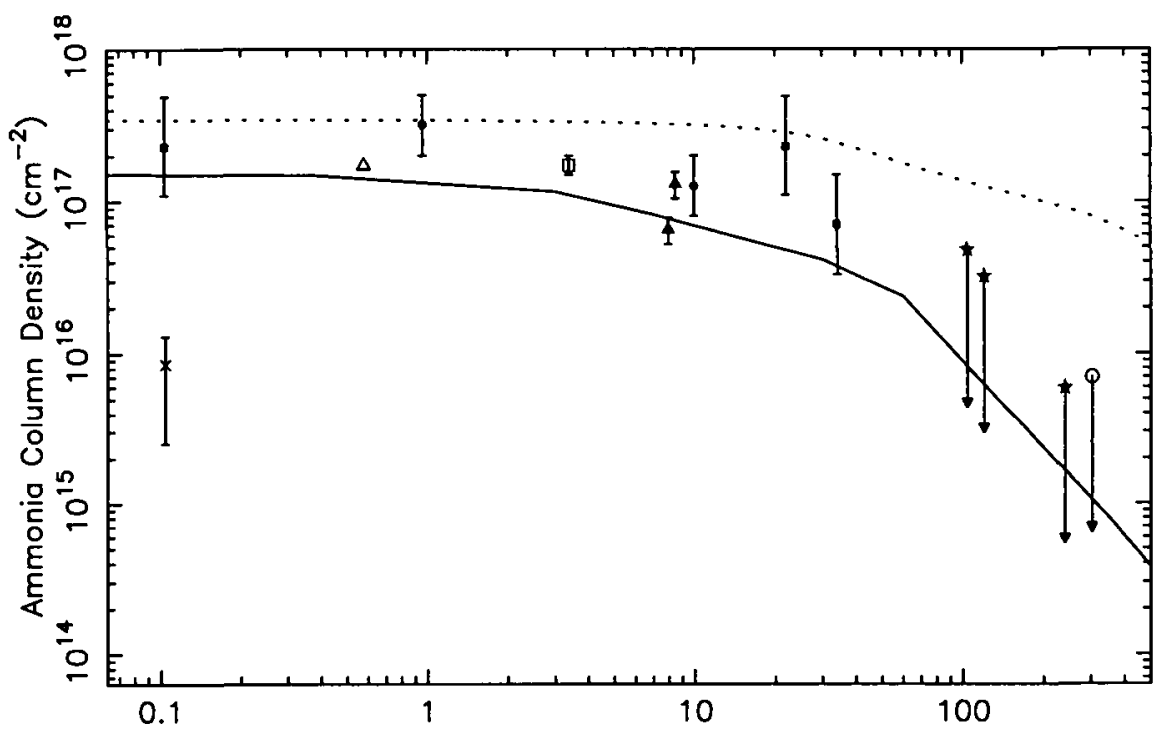

Days After Impoct

Figure 11. The time variation of $\mathrm{NH}_{3}$ (after Fast et al. 1995). The solid line represents the photochemical model results of Model A, and the dotted line the results of Model C. Observations are indicated by individual points and associated error bars. The cross is from Atreya et al. (1995), the solid squares from Yelle \& McGrath (1996) (where the range is calculated assuming the $\mathrm{NH}_{3}$ is confined between $5 \mathrm{mbar}$ and either 12 or $40 \mathrm{mbar}$ ), the open triangle from Conrath et al. (1995, personal communication to T. Kostiuk), the solid circles from Griffith et al. (1995a), the open square from Betz et al. (1995), the solid triangles from Kostiuk et al. (1995), the solid stars (upper limits) from Fast et al. (1995), and the open circle (upper limit) from Bézard et al. (1995). Note: Most of the observations are quoted for columns above 40-150 mbar; the Atreya et al. values are for the column above 0.3-10 mbar. Note also that observations made in the first few weeks were often centered at different impact sites.

so, the model predicts a factor of $\sim 2.6$ decrease in the OCS column after 30 days. This decrease may be consistent with the observations (Lellouch 1996).

Although the $\mathrm{H}_{2} \mathrm{~S}$ detection is controversial, Yelle \& McGrath (1996) suggest that $\mathrm{H}_{2} \mathrm{~S}$ is present in the HST FOS spectra 3.5 hours after the impact, but not 22 days later. This suggestion is consistent with photochemical models.

The time variation of ammonia has been monitored extensively at infrared and ultraviolet wavelengths. Figure 11 shows how the photochemical model results compare with observations. Observations taken many months after the impacts show no evidence for $\mathrm{NH}_{3}$ in the middle and upper stratosphere (Fast et al. 1995, Bézard et al. 1995). However, $\mathrm{NH}_{3}$ is visible in ultraviolet spectra taken 9 months after the impacts (McGrath et al. 1995), suggesting that $\mathrm{NH}_{3}$ may still be enhanced in the lower stratosphere and/or upper troposphere relative to pre-impact values. This latter conclusion will not be confirmed until the data are fully analyzed. As discussed in Section 4.2, the observed time variation of $\mathrm{NH}_{3}$ appears more consistent with Model A than Model $\mathrm{C}$, suggesting that too much dust shielding has been included in the latter model. If we take the models at face value, the model-data comparisons tell us that the dust cannot be optically thick above a few mbar a week or so after the impacts. However, keep in mind that horizontal spreading has not been included in the photochemical models. It is not clear how fast the material at a few mbar to a few 10's of mbar (where most of the $\mathrm{NH}_{3}$ is located 
according to the infrared observations) is spreading. If there is a factor of $\sim 80$ areal spreading 6-12 months after the impacts compared with the spot size during the week of the impacts, then Model $\mathrm{C}$ may easily be consistent with observations.

$\mathrm{HCN}$, like CS, has been monitored at millimeter and submillimeter wavelengths on a regular basis (Marten et al. 1995, Matthews et al. 1995). The HCN column abundance has appeared to drop by a factor of $\sim 10$ in the 6-12 months following the impacts (Matthews et al. 1995, R. Moreno et al. 1995). If horizontal spreading is assumed to have caused the areal extent of the impact sites to increase by a factor of $\sim 80$, then the $\mathrm{mm}$ and sub-mm observations indicate that the HCN abundance (e.g., total mass) may have increased by as much as a factor of $\sim 8$ over time. IRTF/IRSHELL $10-\mu \mathrm{m}$ observations also indicate that $\mathrm{HCN}$ persists in the jovian stratosphere and that the total HCN mass may have increased in the 10 months following the impacts (Griffith et al. 1995b).

These results are consistent with the suggestion of Moses et al. that HCN is produced from $\mathrm{NH}_{3}$ photolysis. The relative increase in the total HCN column depends on the initial $\mathrm{NH}_{3} / \mathrm{HCN}$ ratio. To produce $\mathrm{HCN}$, the photochemical models require a source of atomic nitrogen. In the Moses et al. models, $\mathrm{N}$ is supplied by speculative reactions involving ammonia photolysis products and sulfur, and have NS as an intermediate. Positive or negative searches for NS and other nitrogen-sulfur molecules in observational data would help constrain possible chemical pathways for the production of HCN.

The molecule with the most surprising observed temporal variation as compared with photochemical models is CO. Millimeter and submillimeter observations in the year following the impacts indicate that the impact sites have a $\mathrm{CO}$ column abundance that is $\sim 160$ times less than in July, 1994 (R. Moreno et al. 1995, Matthews et al. 1995, Lellouch 1996). When spreading is taken into account, the implied reduction in total abundance (mass) is a factor of $\sim 2$. Photochemical models do not reproduce a loss of this magnitude loss over the course of a year. In fact, Model $\mathrm{C}$ predicts that the $\mathrm{CO}$ abundance will increase with time due to $\mathrm{H}_{2} \mathrm{O}$ photolysis products reacting with hydrocarbons to form CO. Lellouch (1996) discusses this problem in detail.

How could CO decrease with time while HCN and CS do not? One possible way to reconcile the problem is to assume that the bulk of the $\mathrm{CO}$ is located at a different altitude than that of the CS and HCN. In that case, the temperature variation and rate of horizontal spreading may be different. For instance, HCN and CS are favored by moderately shocked conditions in a "dry" plume; i.e., one that has $\mathrm{C} / \mathrm{O}>1$ (Zahnle 1996, Lyons \& Kansal 1996). If the oxygen is derived from the comet rather than from the jovian atmosphere, then much of the $\mathrm{CO}$ may have come from a different region of the plume/fireball (i.e., one with $\mathrm{C} / \mathrm{O}<1$ ) and hence may have been deposited in a different altitude region during the plume splashback. Zahnle (1996) suggests that the cometary material may have been shocked to very high temperatures, and thus represents the material that has been flung the farthest and deposited the highest in the atmosphere. In addition, the molecules may be filling different areal fractions of the observed impact "scars." One can then imagine scenarios in which the CO spreads and dilutes more rapidly than the CS or HCN. One problem with such scenarios is that the altitudes derived from the millimeter observations (R. Moreno et al. 1995) are similar for the $\mathrm{CO}, \mathrm{CS}$, and $\mathrm{HCN}$, and we know that $\mathrm{HCN}$ has spread over a large area (Griffith et al. 1995b).

Alternatively, some loss mechanism for the $\mathrm{CO}$ that has not been included in the Moses et al. photochemical models may be present in the jovian atmosphere. If the reduction in the $\mathrm{CO}$ abundance is due to photochemical processes, then observations should show a corresponding increase in some other oxygen compound such as $\mathrm{CO}_{2}, \mathrm{SO}_{2}$, or $\mathrm{NO}$ (unless 
the $\mathrm{CO}$ is converted to something that will condense in the stratosphere). No increase in any other oxygen compounds have been found, but it is not clear that anyone has been looking. Recently ( $\sim 15$ months after the impacts), IRAM observations taken under good seeing conditions showed no evidence for $\mathrm{SO}_{2}$ in the jovian stratosphere (E. Lellouch and R. Moreno, personal communication).

\section{Conclusions}

The collision of comet Shoemaker-Levy 9 with Jupiter resulted in profound changes to the jovian atmosphere. To fully understand the chemical changes that occurred after the impacts, photochemical models of the post-SL9 jovian stratosphere have been developed (Moses et al. 1995a,b,c). These models are used to trace chemical changes over time and to connect observations taken days or weeks after the impacts with chemical abundances at the time of the plume splashdown.

The theoretical models indicate that the photochemistry at the impact sites is rapid and complex. The sulfur species introduced by the impacts evolve very quickly. Condensed $S_{8}$ is the main reservoir for the sulfur over time, and the aerosols should become progressively coated with sulfur compounds (e.g., $\mathrm{S}_{8}, \mathrm{H}_{2} \mathrm{~S}_{\mathrm{x}}, \mathrm{N}-\mathrm{S}$ and C-S polymers). One important prediction, that the CS abundance persists with time, seems to be supported by mm and sub-mm observations (R. Moreno et al. 1995, Matthews et al. 1995); however, the dramatic increase of the modeled CS abundance with time is not mirrored in the observations, indicating that the initial $\mathrm{S}_{2} / \mathrm{CS}$ ratio at the impact sites was probably $\lesssim 1$. The observed abundances of $\mathrm{CS}_{2}, \mathrm{OCS}$, and perhaps $\mathrm{H}_{2} \mathrm{~S}$ all seem to decrease roughly as expected. Two predictions remain to be investigated: (1) unusual nitrogensulfur species such as NS and HNCS are predicted to become important reservoirs for both the sulfur and the nitrogen at the impact sites, and (2) $\mathrm{SO}_{2}$ will become an important reservoir for the sulfur if $\mathrm{H}_{2} \mathrm{O}$ was an important initial constituent at the impact sites. Positive or negative searches for these molecules in data taken months after the impacts will help distinguish between several possible chemical schemes that may have occurred at the impact sites and will help constrain the initial water abundance.

Nitrogen compounds tend to be more stable at the impact sites than sulfur compounds. $\mathrm{NH}_{3}$ photolysis, which operates on a week time scale, drives the nitrogen photochemistry. $\mathrm{N}_{2}$ is predicted to be the main nitrogen reservoir over time. In the photochemical models, the HCN abundance increases slightly with time due to reactions catalyzed by sulfur radicals; the $\mathrm{HCN}$ observations appear to be consistent with this prediction (Matthews et al. 1995, R. Moreno et al. 1995, Griffith et al. 1995b). The observed rate of decrease of $\mathrm{NH}_{3}$ may indicate that the dust introduced by the impacts was not optically thick at a few mbar at near-ultraviolet wavelengths after the first week of the impacts. This conclusion will not be firm until we have a better handle on the amount of horizontal spreading at the impact sites.

$\mathrm{H}_{2} \mathrm{O}$ and $\mathrm{CO}$ are predicted to be very stable in the jovian stratosphere. Water, which has a photolysis lifetime of months, will drive the oxygen photochemistry. If large quantities of $\mathrm{H}_{2} \mathrm{O}$ were present throughout the impact sites, then $\mathrm{CO}_{2}, \mathrm{SO}_{2}, \mathrm{SO}$, and $\mathrm{NO}$ will become important oxygen reservoirs over time. The observed decrease in the CO abundance with time (R. Moreno et al. 1995, Matthews et al. 1995, Lellouch 1996) is not consistent with photochemical models. The models may be neglecting some scheme that converts the $\mathrm{CO}$ to other as-yet-unobserved oxygen compounds, or the $\mathrm{CO}$ may have been deposited at a different location than the HCN and CS and so may have experienced a different rate of horizontal spreading. 
Improved photochemical models should help resolve some of the problems with the current model-data comparisons. More realistic initial vertical profiles for the different observed species can be developed now that more sophisticated observational analyses are being published. Future photochemical models should also include parameterizations to take horizontal spreading into account and should allow for diurnal variations. More extensive thermochemical modeling should also help constrain the initial conditions required for accurate photochemical modeling. The Shoemaker-Levy 9 impacts have provided us with a unique opportunity to observe some unusual atmospheric photochemistry in action; photochemical models can be valuable tools in interpreting the chemical evolution at the impact sites.

We thank R. Yelle, K. Zahnle, E. Lellouch, and M. Allen for thorough reviews of the manuscript and many useful discussions.

\section{REFERENCES}

Atreya, S. K., Edgington, S. G., Trafton, L. M., Caldwell, J. J., Noll, K. S., \& WEAVER, H. A. 1995 Abundances of ammonia and carbon disulfide in the Jovian stratosphere following the impact of comet Shoemaker-Levy 9. Geophys. Res. Lett. 22, 1625-1628.

Betz, A. L., Boreiko, R. T., Bester, M., Danchi, W. C., \& Hale D. D. 1995 Stratospheric ammonia in Jupiter after the impact of comet SL-9. Bull. Amer. Astron. Soc. 26, 15901591.

Bézard, B., Griffith, C., Greathouse, T., Kelly, D., Lacy, J., \& Orton, G. 1995 Jupiter ten months after the collision of comet SL9: Stratospheric temperatures and ammonia distribution. Bull. Amer. Astron. Soc. 27, 1126.

Bjoraker, G. L., Herter, T., Gull, G., Stolovy, S. \& Pirger, B. 1995 Detection of water in the "splash" of fragments $G$ and $K$ of comet Shoemaker-Levy 9. In Abstracts for IAU Colloquium 156: The Collision of Comet P/Shoemaker-Levy 9 and Jupiter, p. 8.

Borunov, S., Drossart, P., Encrenaz, Th., \& Dorofeeva, V. 1995 Thermochemistry in the fireball of SL9 impacts. Bull. Amer. Astron. Soc. 27, 1120.

Brooke, T. Y., Orton, G. S., Crisp, D., Friedson, A. J. \& Bjoraker, G. 1995 Nearinfrared spectroscopy of the Shoemaker-Levy 9 impact sites with UKIRT: CO emission from the $\mathrm{L}$ site. In Abstracts for IAU Colloquium 156: The Collision of Comet P/ShoemakerLevy 9 and Jupiter, p. 12.

Caldwell, J., Martyn, M., Delrizzo, D., Atreya, S., Edgington, S., Barnet, C., Noll, K., Weaver, H., Trafton, L., \& Yost, S. 1995 Upper limits on SiO, $\mathrm{H}_{2} \mathrm{~S}, \mathrm{C}_{2} \mathrm{H}_{2}$ and $\mathrm{H}_{2} \mathrm{O}$ on Jupiter from SL9. Bull. Amer. Astron. Soc. 27, 1118-1119.

Carlson, R. W., Weissman, P. R., Hui, J., Segura, M., Smythe, W. D., Baines, K. H., Johnson, T. V., Drossart, P., Encrenaz, T., Leader, F. \& Mehlman, R. 1995 Galileo infrared observations of the Shoemaker-Levy $9 \mathrm{G}$ and $\mathrm{R}$ fireballs and splash. In $A b$. stracts for IAU Colloquium 156: The Collision of Comet P/Shoemaker-Levy 9 and Jupiter, p. 15.

Conrath, B. J., Gierasch, P. J., Hayward, T., McGhee, C. Nicholson, P. D. \& Van Cleve, J. 1995 Palomar mid-infrared spectroscopic observations of comet ShoemakerLevy 9 impact sites. In Abstracts for IAU Colloquium 156: The Collision of Comet $P /$ Shoemaker-Levy 9 and Jupiter, p. 24.

Cosmovici, C. B., Montebugnoli, S., Pogrebenko, S. \& Colom, P. 1995 Water MaSer detection at $22 \mathrm{GHz}$ after the SL-9/Jupiter collision. Bull. Amer. Astron. Soc. 27, 1133.

Fast, K. E., Livengood, T. A., Kostiuk, T., Buhl, D., Espenak, F., Buoraker, G. L., Romani, P. N., Jennings, D. E., Sada, P., Zipoy, D., Goldstein, J. J., \& Hewegama, T. $1995 \mathrm{NH}_{3}$ in Jupiter's stratosphere within the year following the SL9 impacts. Bull. Amer. Astron. Soc. 27, 1126-1127. 
Gladstone, G. R., Allen, M., \& Yung, Y. L. 1996 Hydrocarbon photochemistry in the upper atmosphere of Jupiter. Icarus 119, 1-52.

Griffith, C. A., Bézard, B., Kelly, D., Lacy, J., Greathouse, T., \& Orton, G. 1995a Mid-IR spectroscopy and $\mathrm{NH}_{3}$ and $\mathrm{HCN}$ images of $\mathrm{K}$ impact site. In Abstracts for IAU Colloquium 156: The Collision of Comet P/Shoemaker-Levy 9 and Jupiter, p. 42.

Griffith, C. A., Bézard, B., Greathouse, T., Kelly, D., Lacy, J., \& Orton, G. 1995b Jupiter ten months after the collision of comet SL9: Spectral maps of $\mathrm{HCN}$ and $\mathrm{NH}_{3}$. Bull. Amer. Astron. Soc. 27, 1126.

HEAL, H. G. 1972 The sulfur nitrides. Adv. Inorg. Chem. Radiochem. 15, 375-412.

KiM, S. J., Ruiz, M., RiEkE, G. H., \& RiEkE, M. J. 1995 Thermal history of the R impact flare of comet Shoemaker-Levy 9. Bull. Amer. Astron. Soc. 27, 1120.

Knacke, R. F., Fajardo-Acosta, S. B., Geballe, T. R., \& Noll, K. S. 1995 Infrared spectroscopy of the R-impact of comet Shoemaker-Levy 9. Bull. Amer. Astron. Soc. 27, 1114.

Kostiuk, T., Buhl, D., Espenak, F., Romani, P., Buoraker, G., Fast, K., Livengood, T., \& ZIPOY, D. 1996 Stratospheric ammonia on Jupiter after the SL9 collision. Icarus, submitted.

LeLlouch, E. 1996 Chemistry induced by the impacts: Observations. This volume.

Lellouch, E., Paubert, G., Moreno, R., Festou, M. C., Bézard, B., BockeléeMorvan, D., Colom, P., Crovisier, J., Encrenaz, T., Gautier, D., Marten, A., Despois, D., Strobel, D. F., \& Sievers, A. 1995 Chemical and thermal response of Jupiter's atmosphere following the impact of comet Shoemaker-Levy 9. Nature 373, 592595.

LYONS, J. R., \& KANSAL, A. 1996 A chemical kinetics model for analysis of the comet Shoemaker-Levy 9 impacts with Jupiter. Icarus, submitted.

Maillard, J.-P., Drossart, P., Bézard, B., de Bergh, C., Lellouch, E., Marten, A., Caldwell, J., Hilico, J.-C., \& ATreya, S. K. 1995 Methane and carbon monoxide infrared emissions observed at the Canada-France-Hawaii Telescope during the collision of comet SL-9 with Jupiter. Geophys. Res. Lett. 22, 1573-1576.

Mallama, A., Nelson, P., \& Park, J. 1995 Detection of very high altitude fallout from the comet Shoemaker-Levy 9 explosions in Jupiter's atmosphere. Geophys. Res. Lett. 100, $16,879-16,884$.

Mallard, W. G., Westley, F., Herron, J. T., Hampson, R. F., \& Frizzell, D. H. 1994 NIST Chemical Kinetics Database-Version 6.0. NIST Standard Reference Data, Gaithersburg, MD.

Marten, A., Gautier, D., Griffin, M. J., Matthews, H. E., Naylor, D. A., Davis, G. R., Owen, T., Orton, G., Bockelée-Morvan, D., Colom, P., Crovisier, J., Lellouch, E., de Pater, I., Atreya, S., Strobel, D., Han, B., \& Sanders, D. B. 1995 The collision of comet Shoemaker-Levy 9 with Jupiter: Detection and evolution of HCN in the stratosphere of the planet. Geophys. Res. Lett. 22, 1589-1592.

Matthews, H. E., Marten, A., Griffin, M. J., Owen, T., \& Gautier, D. 1995 JCMT observations of long-lived molecules on Jupiter in the aftermath of the comet ShoemakerLevy 9 collision. Bull. Amer. Astron. Soc. 27, 1121.

McGrath, M. A., Yelle, R. V., Noll, K. S., Weaver, H. A., \& SMith, T. E. 1995 Hubble Space Telescope spectroscopic observations of the Jovian atmosphere following the SL9 impacts. Bull. Amer. Astron. Soc. 27, 1118.

Meadows, V. S., \& CRISP, D. 1995 Near-infrared imaging spectroscopy of the impacts of SL9 fragments C, D, G, K, N, R, V, and W with Jupiter. Bull. Amer. Astron. Soc. 27, 1127.

Moltzen, E. K., Klabunde, K. J., \& Senning, A. 1988 Carbon monosulfide: A review. Chem. Rev. 88, 391-406.

Moreno, F., Muñoz, O., Molina, A., López-Moreno, J. J., Ortiz, J. L., Rodríguez, J., LóPez-Jiménez, A., Girela, F., Larson, S. M., \& CAMPins, H. 1995 Physical properties of the aerosol debris generated by the impact of fragment $\mathrm{H}$ of comet P/Shoemaker-Levy 9 on Jupiter. Geophys. Res. Lett. 22, 1609-1612. 
Moreno, R., Marten, A., Lellouch, E., Paubert, G., \& Wild, W. 1995 Long-term evolution of $\mathrm{CO}$ and $\mathrm{CS}$ in the Jupiter stratosphere after the comet Shoemaker-Levy 9 collision: Millimeter observations with the IRAM-30m telescope. Bull. Amer. Astron. Soc. 27, 1129.

Moses, J. I., Allen, M., \& Gladstone, G. R. 1995a Post-SL9 sulfur photochemistry on Jupiter. Geophys. Res. Lett. 22, 1597-1600.

Moses, J. I., Allen, M., \& Gladstone, G. R. 1995b Nitrogen and oxygen photochemistry following SL9. Geophys. Res. Lett. 22, 1601-1604.

Moses, J. I., Allen, M., Fegley, B., JR., \& Gladstone, G. R. 1995c Photochemical evolution of the post-SL9 Jovian stratosphere. Bull. Amer. Astron. Soc. 27, 1119.

Nicholas, J. E., Amodio, C. A., \& BaKen, M. J. 1979 Kinetics and mechanism of the decomposition of $\mathrm{H}_{2} \mathrm{~S}, \mathrm{CH}_{3} \mathrm{SH}$ and $\left(\mathrm{CH}_{3}\right)_{2} \mathrm{~S}$ in a radio-frequency pulse discharge. J. Chem. Soc. Faraday Trans. 1 75, 1868-1875.

Noll, K. S., McGrath, M. A., Trafton, L. M., Atreya, S. K., Caldwell, J. J., Weaver, H. A., Yelle, R. V., BaRnet, C., \& Edgington, S. 1995 HST spectroscopic observations of Jupiter after the collision of Comet Shoemaker-Levy 9. Science 267, 1307-1313.

Ortiz, J. L., Muñoz, O., Moreno, F., Molina, A., Herbst, T. M., Birkle, K., BöhnhardT, \& Hamilton, D. P. 1995 Models of the SL-9 collision-generated hazes. Geophys. Res. Lett. 22, 1605-1608.

OrTon, G. \& 57 CO-AUTHORs. 1995 Collision of comet Shoemaker-Levy 9 with Jupiter observed by the NASA Infrared Telescope facility. Science 267, 1277-1282.

Sprague, A. L., Bjoraker, G. L., Hunten, D. M., Witteborn, F. C., Kozlowski, R. W. H. \& WoODEN, D. H. 1995. Water brought into Jupiter's atmosphere by fragments $\mathrm{R}$ and $\mathrm{W}$ of comet SL-9 Icarus, in press.

TURNER, B. E. 1989. Recent progress in astrochemistry. Space Sci. Rev. 51, 235-337.

West, R. A., Karkoschka, E., Friedson, A. J., Seymour, M., Baines, K. H. \& Hammel, H. B. 1995 Impact debris particles in Jupiter's stratosphere. Science 267, 1296-1301.

Yang, S. C., Freedman, A., KaWASAkI, M., \& Bersohn, R. 1980 Energy distribution of the fragments produced by photodissociation of $\mathrm{CS}_{2}$ at $193 \mathrm{~nm}$. J. Chem. Phys. 72, 4058-4062.

Yelle, R. V., \& McGrath, M. A. 1995 Results from HST spectroscopy of the SL9 impact sites. Bull. Amer. Astron. Soc. 27, 1118.

Yelle, R. V., \& MCGRath, M. A. 1996 Ultraviolet spectroscopy of the SL9 impact sites. I. The 175-230 $\mathrm{nm}$ region. Icarus $119,90-111$.

ZAHNLE, K. 1995 Dynamics and chemistry of SL9 plumes. This volume.

ZahNle, K., Mac Low, M.-M., LodDers, K., \& FEgley, B., JR. 1995 Sulfur chemistry in the wake of comet Shoemaker-Levy 9. Geophys. Res. Lett. 22, 1593-1596. 